\title{
DNA Repair, Human Diseases and Aging
}

\author{
Vaidehi Krishnan, Baohua Liu and Zhongjun Zhou \\ Department of Biochemistry, The University of Hong Kong \\ Hong Kong
}

\section{Introduction}

One of the most fundamental functions of a cell is the transmission of genetic information to the next generation, with high fidelity. On the face of it, this seems a challenging task given that cells in the human body are constantly exposed to thousands of DNA lesions every day both from endogenous and exogenous sources. Yet, for long periods of time, the DNA sequences are one of the most invariable and stable components of a cell, a task achieved by an arsenal of DNA damage detection and repair machinery that detects and fixes DNA lesions with high fidelity at each and every round of cell division. In this chapter, we describe how normal cells cope with DNA damage and the manner in which a defective DNA damage response can lead to human disease and aging.

\section{The types and sources of DNA damage}

All livings cells of the human body have to constantly contend with DNA damage. Due to its chemical structure itself, the DNA is sensitive to spontaneous hydrolysis which leads to damage in the form of abasic sites and base deamination. Single strand breaks (SSBs) and oxidative damage such as 8-oxoguanine lesions in DNA are generated by endogenous byproducts of metabolism like reactive oxygen species (ROS) and their highly reactive intermediates. For example, it is estimated that about 100-500 8-oxoguanine lesions form per day in a human cell (Lindahl, 1993). The formamidopyrimidine lesions, 2,6-diamino-4hydroxy-5-formamidopyrimidine (FapyG) and 4,6-diamino-5-formamidopyrimidine are also formed at similar rates as 8-oxoG after oxidative stress. Spontaneous DNA alterations may also arise due to dNTP misincorporation during DNA replication. Put together, it is estimated that each human cell can face up to $10^{5}$ spontaneous DNA lesions per day (Maynard et al., 2009).

Apart from endogenous sources, DNA can also be damaged by exogenous agents from the environment. These include physical genotoxic stresses such as the ultraviolet light (mainly UV-B: $280-315 \mathrm{~nm}$ ) from sunlight which can induce a variety of mutagenic and cytotoxic DNA lesions such as cyclobutane-pyrimidine dimers (CPDs) and 6-4 photoproducts (64PPs) (Rastogi et al., 2010). DNA damage in the form of double strand breaks (DSBs) can be incurred as a result of medical treatments like radiotherapy, ionising radiation (IR) exposure from cosmic radiation or as a result of the natural decay of radioactive compounds. For example, uranium decay produces radioactive radon gas, which accumulates in some houses to cause an increased incidence of lung cancer (Jackson and Bartek, 2009). Nuclear 
disasters like the Chernobyl nuclear disaster, nuclear detonations during World War II or more recently, the radiation leakage from the Fukushima power plant in Japan are examples of other sources of severe exposure to exogenous radiation. Chemical sources of DNA damage include chemotherapeutic drugs used in cancer therapy or for other medical conditions. Alkylating agents such as methyl methanesulfonate (MMS) induce alkylation of bases, whereas drugs such as mitomycin C, cisplatin and nitrogen mustard cause DNA interstrand cross links (ICLs), and DNA intrastrand cross links. Chemotherapeutic drugs like camptothecin and etoposide are topoisomerse I and II inhibitors respectively, and give rise to SSBs or DSBs by trapping topoisomerase-DNA complexes. Other exogenous DNAdamaging sources, that are carcinogenic as well, are foods contaminated with fungal toxins such as the aflatoxin and overcooked meat products containing heterocyclic amines. Another common source of environmental mutagen is tobacco smoke, which generates DNA lesions in the form of aromatic adducts on DNA and SSBs (Jackson and Bartek, 2009).

\section{DNA repair pathways}

To maintain genomic integrity, a cellular machinery composed of multi-protein complexes that are capable of detecting and signalling the presence of DNA lesions and delaying cell cycle progression to promote DNA repair is activated, called as the DNA damage response (DDR) (Harper and Elledge, 2007). To accomplish DNA repair, cells utilise biochemically distinct pathways specific of the DNA lesion, which are integrated with appropriate signalling systems to delay cell division until the completion of repair (Figure.1). Small chemical alterations caused by the oxidation of bases is detected and repaired by the base excision repair system (BER), through the direct excision of the damaged base. DNA replication errors or polymerase slippage errors that commonly result in single base mismatches and insertion-deletion loops are corrected by the mismatch repair system (MMR). Lesions such as pyrimidine dimers and intrastrand cross links are corrected by the nucleotide excision repair (NER) pathway. SSBs are removed by the SSB repair pathway whereas DSBs are repaired by the DSB repair systems, which itself could be either by homologous recombination (HR) or non-homologous end joining (NHEJ) pathway (Ciccia and Elledge, 2010).

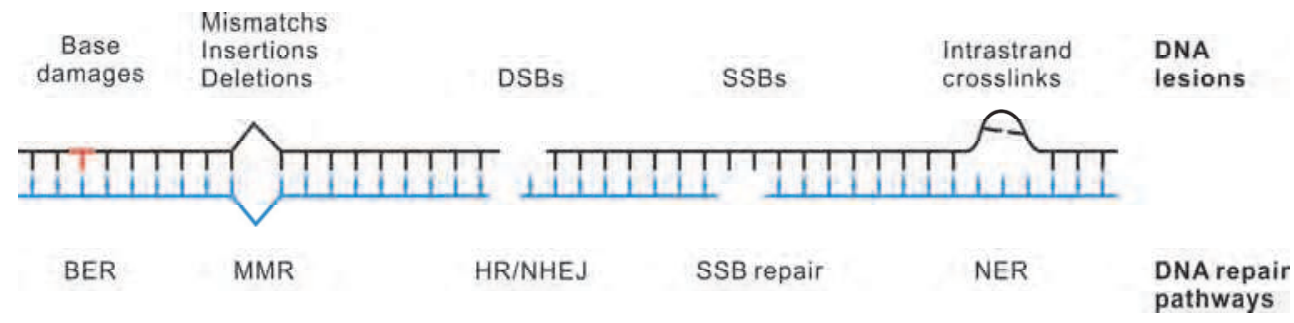

Fig. 1. Summary of DNA repair pathways

\subsection{Base excision repair and single strand break repair}

Base excision repair (BER) is the major pathway responsible for handling the mutagenic and cytotoxic effects of DNA damage that can arise due to spontaneous hydrolytic, oxidative, and non-enzymatic alkylation reactions. (Wilson and Bohr, 2007). This pathway focuses on 
DNA lesions that do not tend to cause structural distortions of the DNA double helix. The BER target lesions can be classified as oxidised/reduced bases such as 8-oxo-G/FapyG, methylated bases, deaminated bases or bases mismatches. There are two types of BER: short patch and long patch. During short patch BER, only the damaged nucleotide is replaced, whereas in long patch BER, 2-6 new nucleotides are incorporated.

The very first step in BER involves the use of DNA glycosylases that cleave the $N$-glycosyl bond between the damaged base and sugar to generate an abasic site, called as the AP (apurinic/apyrimidinic) site. Similar AP sites may also arise due to the spontaneous depurination or depyrimidination of bases. The DNA glycosylases that perform this function are classified as monofunctional or bifunctional, depending on their mode of action. Monofunctional glycosylases such as UNG only possess the glycosylase activity and therefore a second enzyme called the APE1 lyase is required to cut base-free deoxyribose to generate the 5 '-deoxyribose phosphate termini (dRP). The next step involves the action of DNA polymerase $\beta$ (pol $\beta$ ) which removes the dRP group left behind by APE1 incision in the short-patch pathway. However, if the $5^{\prime}$ terminal is refractory to pol $\beta$ activity, strand displacement synthesis is required in order to incorporate multiple nucleotides by longpatch pathway. In this case, several enzymes such as proliferating cell nuclear antigen (PCNA), FEN1 and pol $\beta$ and/or pol $\delta / \varepsilon$ act together to remove the blocking terminus. The final step of BER consists of ligation of the remaining nick, by either Lig1 alone or Lig3XRCC1 complex (Maynard et al., 2009).

SSB repair pathway is a major pathway responsible for the repair of SSBs that arise directly as a result of ROS-induced disintegration of oxidized deoxyribose or genotoxic stresses such as IR. SSBs may also arise spontaneously due to the erroneous activity of DNA topoisomerase 1 (TOP1). TOP1 creates a cleavage complex intermediate which contains a DNA nick to allow DNA relaxation during DNA replication and transcription. Usually, the nick generation is transient and is rapidly sealed by TOP1. However, if the nick inadvertently collides with RNA polymerase, SSBs may be generated in the process. In addition to the above scenarios where SSBs are generated directly within cells, SSBs may also arise indirectly as BER intermediates due to the lyase activity of bifunctional glycosylases such as OGG1 and NEIL1.

Single strand break repair (SSB) involves the activation of PARP (poly ADP ribose polymerase) family members PARP1 and PARP2, which act as sensors of SSBs, through the two PARP1 zinc finger motifs (Caldecott, 2008). Upon activation of PARP1 and PARP2, poly (ADP-ribose) chains are synthesized within seconds, and assembled on target proteins such as histone H1 and H2B and PARP1 itself (Schreiber et al., 2006). Histone PARylation contributes to chromatin reorganization and helps in the recruitment of DNA repair and chromatin remodelling proteins to DNA damage sites. Three types of PAR-binding motifs have been identified: the PBZ (PAR-binding zinc finger), the macrodomain and an 8 amino acid basic residue-rich cluster. Many DDR factors such as p53, XRCC1, Lig3, MRE11 and ATM have the 8 amino acid basic residue-rich cluster, whereas macrodomains containing proteins include PARP9, PARP14, PARP15, the histone variant macroH2A1.1, and the chromatin remodeling factor ALC1. PBZ motifs have been identified in the nucleases APLF and SNM1 and in the cell cycle protein CHFR.

Once SSBs are detected, they undergo end processing, where the $3^{\prime}$ and/or $5^{\prime}$ termini of SSBs are restored to conventional $3^{\prime}$ hydroxyl and $5^{\prime}$ phosphate moieties for gap filling and DNA ligation to occur. XRCC1 has a particularly important role during DNA end 
processing step, since XRCC1 directly interacts with enzymes such as pol $\beta$, PNK (polynucleotide kinase) and the nucleases APTX and indirectly with DNA ligase III $\alpha$ and TDP1 (tyrosyl-DNA phosphodiesterase) to facilitate end processing. Damage termini present at indirect BER-induced SSB are repaired by APE1, Pol $\beta$, PNKP and APTX. Direct sugar damage-induced SSBs are repaired by APE1, PNKP and APTX. SSBs generated by TOP1 are repaired by TDP1. Finally, end processing is followed by gap filling and ligation, and the enzymes utilized during these two steps overlap with BER (as described above). It is interesting that $\sim 30 \%$ of all human tumors examined express a variant form of DNA polymerase $\beta$ (Starcevic et al., 2004) Moreover, at least two proteins, TDP1 and APTX, involved in SSB repair are mutated in an inherited form of human neurodegenerative disease (discussed in Section 5.1).

\subsection{Mismatch repair}

The replication of DNA sequences in the $S$ phase of cell cycle is subjected to a low but significant level of error that includes the inadvertent incorporation of chemically altered nucleotides in place of the normal counterparts. The cell has two main strategies to detect and remove the miscopied nucleotides. In a 'proofreading' type of monitoring executed by the DNA polymerase $\delta$ (pol- $\delta$ ), the stretch of DNA that has been newly synthesized is scanned, and if misincorporation of nucleotides is detected, the enzyme uses it $3^{\prime}-5^{\prime}$ exonuclease activity to remove the aberrant nucleotide and resynthesize the DNA stretch. However, if the miscopied DNA sequence is overlooked by DNA pol- $\delta$, the MMR pathway is activated that detects and corrects misincorporated nucleotides. The action of this pathway becomes especially critical in regions of DNA that carry repetitive sequences such as mono or dinucleotide repeats. The resulting base substitution mismatches and insertiondeletion mismatches (IDLs) may escape correction by the proofreading mechanism described above, making the repair of such defects the prime function of the MMR machinery (Kunkel and Erie, 2005).

The 'Mut' proteins are the principle active components of the mismatch repair pathway (Kolodner and Marsischky, 1999). The main function of the Mut proteins lies in the ability to detect bulges and loops in the newly formed DNA and in being able to distinguish between recently synthesized DNA from the complementary parent strand. In mammalian cells, two components of the MMR apparatus, MutS and MutL collaborate to correct mismatched DNA. MutS homologs form two major heterodimers, Msh2/Msh6 (MutS $\alpha$ ) and Msh2/Msh3 (MutS $\beta$ ) which scan for the mismatched base on the newly formed daughter strand and bind directly to the mutated DNA. The main difference between the two MutS complexes is that MutSa pathway is mainly involved in the repair of base substitution and small loop mismatches, while the MutS $\beta$ pathway is also involved in large loop repair. After the recruitment of MutS, MutL dimer is loaded to the mutated site through its binding to the MutS-DNA complex. MutL has three forms designated as MutL $\alpha$, MutL $\beta$, and MutL $\gamma$. The MutLa complex is made of two subunits MLH1 and PMS2, the MutL $\beta$ heterodimer is made of MLH1 and PMS1, while MutLy is made of MLH1 and MLH3. MutLa is an endonuclease that facilitates strand-discrimination and nicks the discontinuous strand of the mismatched duplex in a PCNA, RFC and ATP-dependent manner. Lastly, the excision reaction is performed by the $5^{\prime}-3^{\prime}$ single-stranded exonuclease EXO1, whose exonuclease activity is increased by its direct interaction with MutSa. The resulting fragment is excised and a fresh 
attempt at resynthesizing DNA using DNA pol- $\delta$ is made using the parent strand as the template (Fukui, 2010; Larrea et al., 2010).

The MMR pathway is particularly important in mammals, where the mutator phenotype conferred by loss of MMR activity contributes to the initiation and promotion of multistagecarcinogenesis (Venkatesan et al., 2006)

\subsection{Nucleotide excision repair}

The activation of NER pathway seems to require two distinct structural changes in DNA: a significant distortion to the native conformation of DNA and the presence of a chemically altered base. NER is accomplished by a large multisubunit complex composed of almost two dozen subunits. NER comprises of two distinct subpathways that mainly differ in the molecular mechanism used to identify the damaged base. Global genome repair (GGR) repairs DNA damage throughout the genome, whereas transcription-coupled repair (TCR) repairs lesions in regions that are undergoing transcription (Nouspikel, 2009).

Historically, the NER pathway was discovered through the study of a human syndrome involving a severe burning of the skin after only a minimal exposure to sun light. These individuals show dry, parchment like skin (Xeroderma) and freckles (pigmentosa). Individuals suffering from Xeroderma Pigmentosa (XP) have a 1000-fold greater risk of developing skin cancers and inherited defects in any of the so-called XP genes cause this syndrome. Subsequently, elegant somatic cell genetic experiments were performed and seven genetic complementation groups of the human XP, designated XPA to XPG were identified in mammalian cells. According to current understanding, two independent complexes, one composed of the DDB1/DDB2 heterodimer, and the other containing the $\mathrm{XPC} / \mathrm{HR} 23 \mathrm{~B} / \mathrm{Centrin} 2$ proteins are required for the early steps of base damage recognition during NER (Guo et al., 2010; Nouspikel, 2009).

UV-damaged DNA-binding protein (UV-DDB) is a heterodimeric complex composed of DDB1 and DDB2 which upon binding to UV-damaged sites activates a UV-DDB-associated ubiquitin ligase complex that recruits XPC protein to the lesion and promotes ubiquitination of DDB2 and XPC proteins (Sugasawa et al., 2005). Upon polyubiquitination, DDB2 loses its ability to bind to UV-irradiated DNA, whereas XPC upon ubiquitination shows increased DNA binding. In turn, XPC recruits the multiprotein transcription-repair complex called as the TFIIH (transcription factor IIH). Subsequent recruitment of RPA and XPA drive detachment of cyclin-dependent kinase activating (CAK) subcomplex of TFIIH which is essential for GGR. The two helicases within the TFIIH complex (XPB and XPD) unwind the DNA by about $20 \mathrm{bp}$ around the damage to form a stable complex called pre-incision complex 1 (PIC1). Localized unwinding around the damaged base then leads to the exit of XPC-HR23 and the entry of XPG to form PIC2. Finally, XPF-ERCC1 is recruited to form PIC3. At each of these steps ATP is hydrolyzed, and the free energy of ATP hydrolysis is used to unwind the helix as well as to amplify the damage recognition specificity of the enzyme system. Within PIC3, XPG and the ERCC1/XPF complex are both structure-specific endonucleases that carry out dual excision and cut the damaged strand of DNA $3^{\prime}$ and $5^{\prime}$ to the lesion, respectively. This generates a single-stranded oligonucleotide 24-32 nucleotides in length. The incisions are asymmetrical, such that the $3^{\prime}$ incision occurs 2 to 8 nucleotides from the damaged base and the $5^{\prime}$ incision occurs 15 to 24 nucleotides from the damaged base. The resulting gap is filled in by the combined actions of DNA polymerase $\delta$ or $\varepsilon$, proliferating cell nuclear antigen (PCNA), RPA, and DNA ligase I (or a complex of XRCCland DNA ligase III) (Hanawalt and Spivak, 2008). 
Bulky lesions consisting of UV-induced pyrimidine dimers in transcribed regions can lead to RNA polymerase II stalling, evoking the activation of TCR. In TCR, the stalled RNA polymerase is removed and DNA damage is repaired, through a process initiated by the Cockayne syndrome proteins, CSA and CSB. The CSA protein belongs to the 'WD repeat' family of proteins and exhibits structural and regulatory roles while CSB protein which is an ATP-dependent chromatin remodelling factor in the SWI/SNF family. CSB, in turn recruits additional factors such as the histone acetytransferase p300, the CSA-DDB1 E3 ubiquitin/COP9 signalosome complex (O'Connell and Harper, 2007). Similar to GGR, the subsequent steps involve the binding of TFIIH and XPA/RPA to the lesion and the nucleases XPG and XPF/ERCC1 carry out the incision $3^{\prime}$ and $5^{\prime}$ to the damaged lesion. The generated oligonucleotide is removed and the gap is filled in by the combined action of DNA polymerases $\delta$ or $\varepsilon$, PCNA, RPA, and DNA ligase I or XRCC1/ DNA ligase III.

\subsection{DNA replication stress and ATR}

Replication stress is a unifying term used to denote large unprotected regions of ssDNA generated during the course of DNA replication or formed at the resected region of DSBs (Lopez-Contreras and Fernandez-Capetillo, 2010). Both situations converge with the generation of a RPA-coated ssDNA intermediate which is the triggering signal for the DNA replication checkpoint. The ssDNA-RPA complex plays two critical roles: it recruits ATR by directly binding to the ATR partner, ATRIP. Secondly, it recruits and activates the Rad17 clamp loader which then loads the PCNA-like heterotrimeric ring 9-1-1 (Rad9-Hus1-Rad1) complex to DNA. The 911 complex binds to the ATR activator TopBP1, thus bringing it in close proximity to ATR-ATRIP, leading to ATR activation. Once activated, ATR initiates the DNA replication checkpoint through the phosphorylation of its downstream substrates. In addition to replication checkpoint signalling, ATR is also required for stabilization of stalled replication forks. In the absence of ATR, forks undergo a 'collapse' and are unable to resume replication upon the withdrawal of replication stress (Friedel et al., 2009). The absence of ATR also results in a specific type of genomic instability, named as DNA Fragile site expression. DNA fragile sites (DFS) are large $(>100 \mathrm{~Kb}$ ) genomic regions that exhibit breaks under conditions of replication stress. DFS sites are 'hot spots' for sister chromatid exchanges and are involved in gene amplification events via a breakage-fusion-bridge cycle. Breakage at DFS is associated with several cancers (Dillon et al., 2010).

\subsection{Interstrand cross link repair (ICL repair)}

ICLs are generated by cross linking agents like mitomycin $C$ and these lesions covalently connect the two strands of DNA to form a barrier to replication fork progression. Important components of the ICL repair pathway are 13 genes mutated in the genetic syndrome, Fanconi anemia (FA). FA is an autosomal recessive cancer predisposition disorder characterized by progressive bone marrow failure, congenital developmental defects, chromosomal abnormalities and hypersensitivity to ICL agents (Kitao and Takata, 2011). The gene products of FA constitute a common pathway called the FA pathway, whose main role is in the repair of ICL lesions to maintain genomic integrity (Moldovan and D'Andrea, 2009). Eight of the FA proteins (FANCA, B, C, E, F, G, L and M) form the so-called FA core complex, an E3 ubiquitin ligase that monoubiquitinates downstream FANCD2-FANCI dimer. The core complex also incorporates FAAP100 and FAAP24 and the heterodimer MHF1/MHF2 as crucial components. Upon monoubiquitination, the ID complex 
accumulates at the sites of crosslinks and co-localizes with three additional FA proteins, Brca2 (FANCD), PALB2 (FANCN), and BACH1 (FANCJ). Monoubiquitinated ID complex is required for the incision and translesion synthesis steps of ICL repair by promoting the recruitment of DDR factors required for ICL repair (Moldovan and D'Andrea, 2009). Recently, another level of regulation was revealed in the FA pathway, in that ID complex is phosphorylated first by ATR and this step was shown to be critical for further monoubiquitination by the core complex. Subsequently, factors required for HR are also recruited to repair the DSBs generated during the repair process. Thus, ICL repair requires the coordinated recruitment and concerted action of several DNA repair pathways.

\subsection{Double strand break repair}

DNA double strand breaks are the most deleterious type of DNA damage and cells have evolved at least four types of repair pathways to detect and correct DSBs. These pathways include homologous recombination (HR), non-homologous end joining (NHEJ), alternative NHEJ pathway. The main factor influencing pathway choice is the extent of DNA processing. While NHEJ does not require DNA end resection, HR and alternative NHEJ pathways are dependent on end resection (Ciccia and Elledge, 2010).

NHEJ is an error-prone process, where broken ends are recognised and sealed together and mainly occurs in G0, G1 and early S phase of the cell cycle and requires the DNA-PK (DNA protein kinase) complex and the Lig4 complex (Lieber, 2010). The DNA-PK complex consists of the Ku70 and Ku80 heterodimer which recognises and binds to the DSB and recruits DNA-PKcs, the catalytic subunit of DNA-PK. Following DSB binding, DNA-PKcs autophosphorylation on the six-residue ABCDE cluster (T2609) causes destabilization of the DNA-PKcs interaction with DNA thus providing access to end processing enzymes such as ARTEMIS (Goodarzi et al., 2006). On the other hand, to prevent excessive end processing, DNA-PKcs is also autophosphorylated at the five-residue cluster called as the PQR cluster at S2056, which helps protect DNA ends. Thus, two reciprocally acting phosphorylation clusters regulate end processing by DNA-PKcs (Cui et al., 2005).

Following the recognition of DSBs, ends must be transformed into 5'phosphorylated ligatable ends to complete repair. One key enzyme required for end processing is ARTEMIS, which might be recruited to DSBs through its ability to interact with DNA-PKcs. End processing is also carried out by APLF nucleases and the PNK kinase/phosphatase prior to ligation (Mahaney et al., 2009). Next, the end processing of complex lesions might lead to the generation of gaps which are filled in by DNA polymerase $\mu$, polymerase $\lambda$ and terminal deoxyribonucleotidyltransferase. The final step involves the ligation of DNA ends, a step carried out by X4-L4 (a complex containing XRCC4, DNA ligase IV and XLF) (Hartlerode and Scully, 2009).

Interestingly, when the classical NHEJ pathway is inhibited, an alternative end-joining pathway operates in cells. This substitution is called as alternative end joining (alt-EJ), backup NHEJ (B-NHEJ) or microhomology mediated end joining (MMEJ) (Lieber and Wilson, 2010). This pathway functions even in the absence of classical NHEJ factors such as $\mathrm{Ku}, \mathrm{XRCC} 4$ or DNA ligase IV. For example, the alt-NHEJ pathway is robustly activated in mice lacking X4-L4. Alt-NHEJ is mediated by the annealing of ssDNA microhomology regions followed by LIG3-dependent DNA end ligation (Ciccia and Elledge, 2010; Hartlerode and Scully, 2009). Microhomologies are short stretches of complementary "microhomology" sequences (1-10 base pairs) that often appear at repair junctions. This suggests that even limited base pairing between two ends of a double-strand break is 
exploited during alt-NHEJ repair (Lieber and Wilson, 2010). Alt-NHEJ pathway is errorprone and frequently results in small deletions/insertions around the region of double strand breaks or could even result in deleterious translocations (Zhang and Jasin, 2011).

Unlike NHEJ, HR is an error-free process that involves the use of the undamaged homologous sister chromatid as the template to facilitate DNA repair of the damaged strand and is carried out in cells that are in the late S and G2 phases of cell cycle (Moynahan and Jasin, 2010). Homologous recombination (HR) provides an important mechanism to repair double strand breaks during mitosis and meiosis. Defective HR can potentially transform cells by disrupting their genomic integrity. HR involves the detection of DSB by the MRN (MRE11-Rad50-NBS1) complex which promotes activation of ATM (Ataxia-telangiectasia mutated). In addition to stabilizing DNA ends, MRE11 has endonuclease and exonuclease activities which are important to mediate $5^{\prime}-3^{\prime}$ resection along with CtIP to generate single strand DNA (ssDNA). ssDNA is coated by the ssDNA-binding protein, RPA which is a heterotrimeric complex (RPA1, RPA2, RPA3) that stabilizes ssDNA regions generated during both DNA replication, repair and recombination. At the double strand break, the RPA-coated ssDNA recruits ATR-ATRIP to chromatin, an event critical for the activation of the ATR-chk1 pathway. Similar to the trimeric RPA complex, the newly identified human ssDNA binding protein, hSSB1 is thought play a role in checkpoint activation and repair (Richard et al., 2008). The next critical step in HR is the assimilation of Rad51 to ssDNA in a Brca2 and PALB2 (Partner and localizer of Brca2) dependent manner to form the Rad51coated nucleoprotein filament. Rad51-mediated homology search and strand invasion follows where the Rad51 recombinase utilizes the sister chromatid as the homologous template and together with Rad51 paralogs (Xrcc2, Xrcc3, Rad51L1, Rad51L2 and Rad51L3), Rad52 and Rad54 promotes strand invasion and recombination. Strand invasion and migration involve the formation of a structure termed as the Holliday junction. Following DNA polymerase $\delta$-mediated DNA synthesis, resolution of Holliday junction occurs via Rad54/Mus81/Emc1 and Rad51C/Xrcc3 (San Filippo et al., 2008).

It is now becoming increasingly clear that the choice between the various DNA repair pathways is dictated by negative regulation of on one pathway by another. For example, DSB resection promoted by CtIP is inhibited by 53BP1 (Bunting et al., 2010). 53BP1 itself promotes NHEJ by increasing the stability of DSBs during ligation. Another example of this regulation was highlighted by a recent study where defective DSB resection in Brca1 mutant cells results in NHEJ-dependent chromosomal rearrangements which could be overcome by 53BP1 loss, suggesting that Brca1 might somehow overcome 53BP1 function at DSBs to promote HR (Bunting et al., 2010). Also, abnormal activity of alt-NHEJ in the absence of NHEJ induces chromosomal translocation in mammalian cells (Simsek and Jasin, 2010). Thus, the right choice of DSB repair pathways can be a critical determinant of genomic stability and alterations in the appropriate repair pathway choice can lead to DSB repair defects with deleterious consequences.

\subsection{Double strand break signalling}

Amongst the various classes of DNA repair, perhaps the best studied pathway with respect to DNA lesion sensing and signalling is the DSB repair signalling response. The response to DSBs has been characterised by the rapid localization of repair factors to DSB sites into subnuclear foci called ionizing radiation-induced foci (IRIF) (Bekker-Jensen and Mailand, 2010). At a more mechanistic level, the DDR proteins can be divided into three major classes 
of proteins that act together to translate the DNA damage signal into an appropriate response. These consist of (a) sensor proteins that recognize abnormal DNA lesions and initiate the signalling cascade (b) transducers that amplify the damage signal and (c) effectors proteins that participate in a number of downstream pathways such as cell cycle, apoptosis and senescence (Figure 2: DNA damage signalling and response) (Jackson and Bartek, 2009).

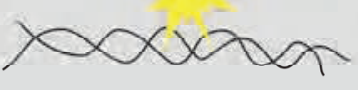

\section{Genotoxic}

stress

$\downarrow$

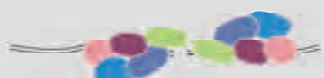

DNA damage sensing
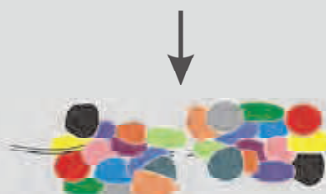

Signal amplification and transduction

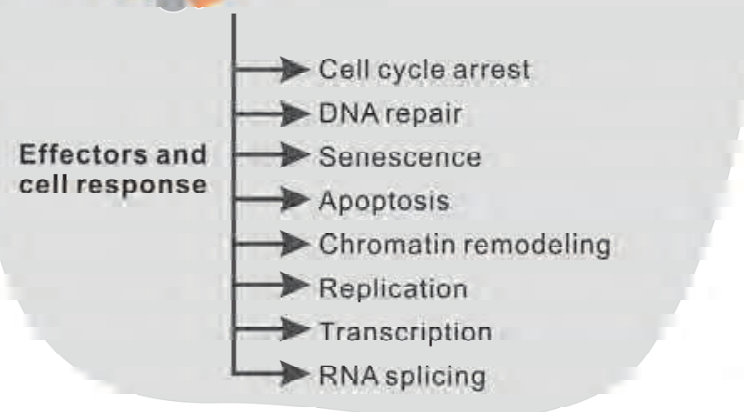

Fig. 2. Basic organization of the DNA damage response: Sensors, transducers and effectors

\subsubsection{Sensing the damage}

The efficient sensing of DSBs is achieved by Mre11-Rad50-Nbs1 (MRN) protein complex (Stracker and Petrini, 2011). The MRE11 (Meiotic Recombination 11) protein is an evolutionarily conserved protein that is involved in HR, NHEJ, meiosis and in the maintenance of telomeres. RAD50 is a homolog of S.cerevisiae Rad50 and is a member of the structural maintenance of chromosome (SMC) protein family. The third protein in the MRN complex is NBS1 (Nijmegen breakage syndrome 1) protein also known as Nibrin and p95. Structural and biochemical studies have elucidated the architecture of the MRN complex and have proposed the biochemical events that lead to the activation of the DDR. The key protein in the MRN complex is the Mre11 homodimer. This protein has the ability to bind free DSBs and also has an intrinsic 3' -5 ' exonuclease activity that can help in the resection of 
broken ends. The Mre11 dimer can interact with two molecules of Rad50 and with the scaffolding protein Nbs1. The extended coiled-coil domains of Rad50 permit it to extend out from DNA breaks and bridge with another Rad50 protein through the $\mathrm{Zn}^{2+}$-binding CXXC motif, like a 'hook'. Thus, Rad50 might act as a molecular tether to bridge the DSBs.

The MRN complex interacts with the N-terminal of ATM and recruits it to DSBs (Lee and Paull, 2004). ATM belongs to the phosphatidylinositol-3-like kinase-related kinases (PIKK) family and plays an important role in the propagation of the initial DSB lesion by phosphorylating a number of downstream substrates. The PIKK family of proteins have a conserved kinase domain and three other domains: FAT (FRAP-ATM-TRRAP) domain, FATC domain (FRAP-ATM-TRRAP-C-terminal) and the PIKK regulatory domain that regulate the kinase activity of the protein. Apart from ATM, the other two PIKK proteins essential for DNA damage signalling are ATR (ATM and Rad3 related) and DNA-PKcs. ATM and DNA-PKcs are primarily involved in the signalling of DSBs and ATR is mainly required in response to stalled DNA replication forks. The interaction between the Cterminus of NBS1 and ATM leads to the recruitment of ATM to DSBs leading to its activation. In undamaged cells, ATM forms inactive dimers or multimers. However, upon the induction of DSBs, ATM is autophosphorylated at serine 1981, leading to its dissociation into activated monomers (Bakkenist and Kastan, 2003). Apart from ser1981, ATM is also autophosphorylated at serine 367 and serine 1983 and mutations at these sites reduce ATM activity. However, observations that transgenic mice carrying alanine substituted autophosphorylation serine sites 1987, 367 and 1899 of ATM (corresponding to human ATM serine 1981, 367 and 1893) display normal ATM-dependent responses, brought into question the function of ATM autophosphorylation in vivo (Daniel et al., 2008). This issue has been reconciled with the observation that autophosporylation of ATM at 1981 is not needed for the initial recruitment of ATM to DSBs, but for the stable association of activated ATM with the damaged chromatin (So et al., 2009). The regulation of ATM autophosphorylation is under the control of three serine/threonine phosphatases, PP2A, PP5 and Wip1, so that ATM is not activated in an untimely manner in the absence of DSBs. Interestingly, defects in the activity of these phosphatases also lead to disease phenotypes in knock-out mice (Peng and Maller, 2010).

\subsubsection{Amplification of the signal}

Activated ATM rapidly phosphorylates and activates several DNA repair factors to directly promote their recruitment to sites of DNA damage. Perhaps, the most important event is the ATM-dependent phosphorylation of the histone variant, $\mathrm{H} 2 \mathrm{AX}$ at the C-terminal of the protein, corresponding to Ser139 $(\gamma$-H2AX) (Rogakou et al., 1998). Remarkably, in mammalian cells, this phosphorylation spreads over a $2 \mathrm{Mb}$ domain of chromatin surrounding the DSB. $\gamma$-H2AX flanked DSB creates a specialized chromatin compartment capable of recruiting and retaining DNA repair factors. Indeed, mice deficient for H2AX develop genomic instability and cancers (Celeste et al., 2002). A large number of proteins have been identified as substrates for activated ATM and this list includes the proteins SMC1, NBS1, CHK2, p53, BRCA1 and MDC1 (Harper and Elledge, 2007). Key amongst these substrates are the Chk2 kinase and p53 which act to reduce cyclin-dependent kinase (CDK) activity. The direct consequence of reduced Cdk activity is that cells arrest in the various stages of cell cycle to allow time of the completion of DNA repair. Amongst the various ATM substrates, MDC1, in particular, is an important mediator of DSB signalling because it 
recognizes and binds $\gamma$-H2AX via its tandem BRCA1 C-terminal (BRCT) domains. The MDC1 C-terminal domain has been crystallized with $\gamma-\mathrm{H} 2 \mathrm{AX}$ and the importance of this interaction was shown by experiments where mutations either in the phospho-acceptor site or in the conserved residues of BRCT domain impaired repair foci recruitment after DSB induction. Moreover, accumulation of several other repair factors such as NBS1, 53BP1 and the phosphorylation of ATM were reduced when MDC1- $\gamma-\mathrm{H} 2 \mathrm{AX}$ interaction was abrogated. The serine-aspartic acid-threonine (SDT) repeats near the N-terminus of MDC1 are phosphorylated by Casein kinase 2, and this enables the interaction of MDC1 with NBS1. This interaction is not controlled by DNA damage, and MDC1 and MRN already exist as a complex in undamaged cells. Upon the generation of $\gamma-\mathrm{H} 2 \mathrm{AX}, \mathrm{MDC} 1$ together with MRN is recruited via the BRCT domain of MDC1. The concentrated binding of ATM to MDC1 and MRN further promotes the phosphorylation of $\mathrm{H} 2 \mathrm{AX}$, resulting in the amplification of the DDR. Thus, MDC1 is an important mediator of the DDR that regulates both the recruitment and retention of several downstream proteins (Huen and Chen, 2010).

Elegant work from the Misteli laboratory has established that the stable tethering of MDC1, MRN or ATM to DNA is sufficient to induce the DDR, even in the absence of DSBs. Upon targeted binding of MRN to a repetitive array, MDC1 and 53BP1 were recruited in an H2AX-dependent manner (Soutoglou and Misteli, 2008). These and other studies have given rise to the current model that MRN binding causes ATM recruitment and activation which initiates $\gamma-\mathrm{H} 2 \mathrm{AX}$ formation. When MDC1 interacts with $\gamma-\mathrm{H} 2 \mathrm{AX}$, it provides a platform for the recruitment of MRN and ATM resulting in further propagation and spreading of $\gamma-\mathrm{H} 2 \mathrm{AX}$. Interestingly, when the kinetics of recruitment of DDR factors to DSBs was studied by live-cell imaging, NBS1 and MDC1 were the first factors to get recruited, seconds after DSB induction. The appearance of 53BP1 and BRCA1 was significantly slower that the MDC1 and NBS1 and more significantly, 53BP1 and Brca1 recruitment were abolished in MDC-null cells. This gave rise to a hierarchical model that the recruitment of 53BP1 and Brca1 was dependent on the stable recruitment of MDC1 through its interaction with $\gamma$-H2AX (Bekker-Jensen et al., 2006).

\subsubsection{Recruitment of 53BP1 and Brca1}

How exactly are Brca1 and 53BP1 recruited to DSB sites? A flurry of papers in recent years solved this conundrum through the identification of a ubiquitination cascade at DSB lesions. The product of the tumor suppressor gene $B R C A 1$ plays a central role in the maintenance of genomic integrity. Brca1 has been shown to regulate several cellular processes including transcriptional regulation, centrosome duplication, HR, NHEJ and checkpoint control. BRCA1 encodes a large protein of 1863 amino acids and contains tandem BRCT domains in its C-terminal region (Huen et al., 2010). In its N-terminus, it harbours a RING finger domain that specifically interacts with the structurally related protein Bard1 (BRCA1associated ring domain protein 1) to heterodimerize and form a functional E3 ubiquitin ligase which forms a complex with $\mathrm{E} 2 \mathrm{UBCH} 5 \mathrm{C}$ to promote the formation of K6-linked ubiquitin chains, an unusual chain linkage. The Brca1-Bard1 heterodimer form three nonoverlapping complexes with distinct functions. The complexes are formed between Brca1 and phosphorylated proteins through the BRCT domain. The complexes include Brca1BRIP, Brca1-CtIP and Brca1-Abraxas-Rap80-BRCC36 complexes. The Brca1-Abraxas-Rap80 complex mainly accumulates at DSBs and promotes the G2/M checkpoint. BRCC36 is a deubiquitinating enzyme and it is speculated that it might regulate Brca1-Bard1 
ubquitination activity. The key mediator of Brca1 recruitment to DSB sites is Rap80. It was found that Rap80 depletion abolished Brca1 focus formation, whereas Brca1 depletion did not affect Rap80 focus formation. This strongly suggested that Rap80 controlled Brca1 focus formation. Upon mapping the site required for focus formation, it was found that the UIM motifs of Rap80 are required. The ubiquitin-binding function of the UIM motif is important to facilitate BRCA1-Rap80 recruitment to DNA lesions and the introduction of mutations that reduce ubiquitin binding also impair Brca1 and Rap80 focus formation. These studies led to the idea that a ubiquitin-dependent signalling system is important for Brca1 recruitment to sites of DSBs (Al-Hakim et al., 2010).

An important breakthrough in this area of research was made upon the identification of RNF8, the first of the three E3 ubiquitin ligases that catalyze regulatory ubiquitination at DNA lesions (Mailand et al., 2007). Importantly, the ubiquitin ligase activity of RNF8 was found to be absolutely essential for the recruitment of both Brca1 and 53BP1 to DSBs. RNF8 contains an FHA domain at its N-terminus and a RING finger motif at its C-terminus. The FHA domain of RNF8 recognises the ATM phosphorylated site of MDC1, leading to its recruitment to IRIF. The FHA domain of RNF8 also interacts with the HECT domain of the second E3 ligase HERC2, thus recruiting HERC2 to DSB sites. RNF8 together with HERC2 facilitates the assembly of the E2 ubiquitin conjugating enzyme Ubc13 to initiate K63-linked ubiquitin chains on H2A and its variants. The third E3 RING domain ubiquitin E3 ligase RNF168 recognizes and binds to K63-linked ubiquitin chains on H2A and H2AX through its two MIUs ((Motif Interacting with Ubiquitin). This amplifies the local concentration of K63linked ubiquitin resulting in the recruitment and retention of 53BP1 and BRCA1 at the sites of lesions. Interestingly RNF168 was first identified as the gene mutated in RIDDLE syndrome (Stewart et al., 2009). RIDDLE (Radiosensitivity, immunodeficiency, dysmorphic features and learning difficulties) is a novel human immunodeficiency disorder associated with defects in DSB repair and Brca1/53BP1 recruitment defects.

Recently, another layer of complexity has emerged in the scenario of post translational modifications occurring following DSB induction. DSB-induced ubiquitylation and the recruitment of BRCA1 and other repair proteins to the sites of damage are also regulated by SUMOylation, placing SUMOylation as a critical post-translational modification necessary for optimal ubiquitylation at DSBs (Tang and Greenberg, 2010). Apart of ubiquitination and sumoylation, methylation of histones is also important for 53BP1 recruitment. According to a recent study, the loading of 53BP1 to DNA lesions is enabled by a local increase in H4K20 dimethylation surrounding the DSBs and this step is catalysed by the histone methyltransferase MMSET (Pei et al., 2011).

\subsection{Coordinating DDR with cell cycle transitions}

One important cellular consequence of DNA damage is the activation of cell cycle checkpoints which are surveillance mechanisms that arrest the cell cycle until repair is satisfactorily accomplished. The cell cycle is regulated through oscillations in cyclin dependent kinase activity (CDK) whose activity is upregulated by cyclins and inhibited by cyclin-dependent kinase inhibitors (CKI) and inhibitory phosphorylation of CDKs (Guardavaccaro and Pagano, 2006). At the molecular level, the DNA damage checkpoint arrests cell cycle transitions by directly reducing CDK activity through various mechanisms mainly initiated by ATM and ATR. Two ATM-dependent G/S checkpoints have been described. ATM activation by DSBs in G1 leads to Chk2 phosphorylation and consequent phosphorylation of the phosphatase CDC25A. This results in the formation of a 
phosphodegron which marks CDC25A for ubiquitin-mediated degradation and prevents the Thr14/Tyr15 dephosphorylation-mediated activation of CDK2. A second mechanism underlying the G1/S checkpoint involves the phosphorylation and stabilization of p53, either directly by ATM or indirectly by Chk2, which in turn acts as the transcription factor for the CKI, p21. This results in delayed G1/S transition after DNA damage. Together, CDC25A degradation and p21 upregulation form the basis for G1/S checkpoint maintenance (Bartek and Lukas, 2007).

During the $S$ phase checkpoint, ATR is activated in response to stalled replication forks leading to the phosphorylation of Chk1 and the subsequent phosphorylation mediated degradation of Cdc25A by the SCF (Skp1-Cullin-F-box) $\beta$-TRCP ubiquitin ligase (Guardavaccaro and Pagano, 2006). This causes the inhibition of CDK2-Cyclin E/A activity preventing the initiation of new replication origins to slow down DNA replication. The failure to regulate Cdc25 leads to hyperactive Cdk activity and defective intra-S phase checkpoint. Yet another regulatory circuit to prevent DNA replication during repair involves the targeted degradation of Cdt1 which loads the replicative helicases MCM2-7 to form the pre-replication complex (Arias and Walter, 2007).

The G2/M checkpoint is initiated by the phosphorylation of checkpoint kinases, Chk1 and Chk2, which phosphorylate and inactivate CDC25C phosphatase by promoting its inhibitory sequestration by 14-3-3 proteins. This prevents the dephosphorylation-mediated activation of CDK1-Cyclin B complex required for mitotic progression (Lukas et al., 2004). Another target of the G2/M checkpoint are the Wee1 kinases. During a normal G2/M transition, Polo kinase 1(Plk1) phosphorylates Wee1 to create a phosphodegron that targets Wee1 for ubiquitin-mediated proteolysis. In the wake of G2/M checkpoint activation, Plk1 is negatively regulated by ATM/ATR and Wee1 accumulates in the cell to maintain CDKs in their inhibited form. Together, these mechanisms act in concert to halt cell cycle progression until the completion of DNA repair (Harper and Elledge, 2007).

\subsection{Identification of novel ATM/ATR substrates using proteomic approaches}

Recently, it has become apparent that DNA damage-activated kinases do not simply contact key individual proteins in a process, but phosphorylate multiple proteins of individual pathways. Importantly, understanding such linkages could have tremendous implications for human disease. In a large scale proteomic study, about 900 phosphorylation sites containing a consensus ATM and ATR phosphorylation motif were identified in 700 substrates that were inducibly phosphorylated after irradiation (Matsuoka et al., 2007). Based on the rationale that ATM and ATR phosphorylate substrates at the consensus SQ/TQ motifs, a phospho-antibody specific directed against this consensus site was used to immunoprecipitate peptides and mass spectrometric analyses was performed. The identified proteins were clustered into modules based on their known function. Multiple modules involved in DNA replication were identified such as the Orc module consisting of Orc3 and Or6, MCM module, including Mcm2, Mcm3, Mcm6, Mcm7 and Mcm10, RFC clamp-loader module consisting of Rfc1 and Rfc3 and the DNA polymerase module composed of the catalytic subunit of DNA polymerase epsilon, its interacting protein PolE4 and two translesion polymerases PolL and PolQ. Other modules included the mismatch repair module consisting of the proteins, Msh2, Msh3 and Msh6 and Exo1, excision repair module included XPA, XPC, RPA1, CSB, components of the transcription factor IIH, a fanconi anaemia module and a HR module. Interestingly, three components of the COP9 signalosome involved in the regulation of SCF (Skp1-Cullin-F-box) E3 ligase function and a 
novel cell cycle module comprising Cyclin E and its negative regulators FBW7, p27kip1 and CIZ1 were also identified as ATM/ATR substrates. Other proteins included components of the spindle checkpoint pathway comprising of Bub1, Mad1, Sgo1 and Mad2BP, Cdc26, separase, and cohesion subunits SMC1 and SMC3. Perhaps, the most interesting group of substrates were proteins in the insulin-IGF-1 (insulin-like growth factor)-PI3K (phosphatidylinositol 3-kinase)-AKT pathway, including the adaptor molecule IRS2 (insulin receptor substrate 2), the kinase AKT3, two regulators of AKT, HSP90 (heat shock protein 90), and PP2A (protein phosphatase 2A), and several downstream effectors of AKT such as FOXO1, and proteins involved in translation control such as TSC1 (tuberous sclerosis 1), 4E-BP1 (eIF4E binding protein 1), and p70S6K (ribosomal protein S6 kinase). This indicates that the DDR is likely to control the insulin-IGF pathway in multiple ways and further studies in this direction will shed light on the role of ATM/ATR pathway in human metabolic syndromes such as diabetes and other age-associated metabolic disorders.

\section{Physiological roles of DDR}

It has now become apparent that the DDR pathway is not just activated in response to genotoxic stress, but that it is essential for several physiological processes. Examples where genome alterations are induced in a programmed manner are $\mathrm{V}(\mathrm{D}) \mathrm{J}$ recombination (Bassing and Alt, 2004), class switch recombination (CSR) (Stavnezer et al., 2008) and somatic hypermutation (SHM) (Di Noia and Neuberger, 2007). These processes occur in developing $\mathrm{T}$ and $\mathrm{B}$ lymphocytes to generate $\mathrm{T}$-cell receptor and immunoglobulin diversity, to allow the recognition of pathogens (Jackson and Bartek, 2009). In the meiotic cells, the DDR plays an important role when homologous chromosomes align and exchange genetic information by recombination. Meiotic HR is generated by the topoisomerase II-like enzyme Spo11, which generates DSBs. In subsequent steps that require MRN complex, HR recombination occurs which requires all mitotic HR proteins along with a Rad51-like protein, DMC (Richardson et al., 2004). In the developing nervous system, high levels of oxidative and metabolic stress are effectively repaired by the DDR. During infections with pathogens such as the avian influenza virus, the DDR proteins modulate the virulence properties of the virus through recombination (Jackson and Bartek, 2009). During bacterial infections, bacterial pathogens with defects in MMR, termed mutators or hypermutators, are overrepresented and are hypothesized to be advantageous for the establishment of chronic infections (Sundin and Weigand, 2007). DDR proteins also play important roles at normal telomeres and thus their defects cause telomere shortening and/or telomere dysfunction associated with chromosome fusions and instability (Jackson and Bartek, 2009). Telomeres are recognized by DDR proteins such as Mre11 (DSB repair), XPF/Ercc1 (NER), Ku70/Ku80 (NHEJ repair), Bloom and WRN RecQ helicases and Rad51D (HR repair) (Denchi, 2009). These factors are recruited to the telomeres through their direct interaction with protein of the shelterin complex, a complex of six telomere binding proteins that promote telomere homeostasis. Recent studies have also established a relationship between DDR and another physiological phenomenon, the circadian rhythm, a process controlled by light stimuli (Sancar et al., 2010). The circadian rhythm regulator clk-2 has been shown to affect radiation sensitivity in C.elegans and $S$ phase checkpoint in response to replication stress in mammalian cells. NER has also been shown to be regulated by the circadian clock and there is strong evidence that the clock protein Cry participates in the maintenance of genomic integrity against DNA 
damage induced by UV and UV mimetics. It has been proposed that such linkages between light cycle and DNA repair can allow cells to respond appropriately to environmentallyinduced DNA damage ((Jackson and Bartek, 2009)). Described in greater detail below are the physiological roles of DDR in the immune system, meiosis and in the maintenance of genome integrity of stem cells.

\section{1 $\mathrm{V}(\mathrm{D}) \mathrm{J}$ recombination and class switch recombination}

One of the cell types where programmed DSBs are generated are B and T lymphocytes. B and $\mathrm{T}$ cells are the main components of the adaptive immune system and responsible for the generation of $\mathrm{B}$ cell receptors (BCRs, also known as immunoglobulins) and $\mathrm{T}$ cell receptors (TCRs), which together recognize a large repertoire of antigens. During the development of antigen receptor genes, a large number of variable $(\mathrm{V})$, diversity $(\mathrm{D})$, joining $(\mathrm{J})$ and constant (C) segments undergo rearrangement by processes termed as V(D)J recombination and class switch recombination (CSR) (Bassing and Alt, 2004; Stavnezer et al., 2008). Immunoglobulin (Ig) contains a heavy chain and either a $\mathrm{k}$ or $\lambda$ light chain. TCRs are composed of either $\alpha \beta$ or $\gamma \delta$ dimers. In humans, Ig heavy chain loci contain $51 \mathrm{~V}_{\mathrm{H}}, 27 \mathrm{D}_{\mathrm{H}}, 6 \mathrm{~J}_{\mathrm{H}}$ and $9 \mathrm{C}_{\mathrm{H}}$ segments and Ig light chain loci contain $40 \mathrm{VK}, 31 \mathrm{~V} \lambda, 5 \mathrm{JK}$ and $4 \mathrm{~J} \lambda$ segments; TCR loci consist of $54 \mathrm{~V} \alpha, 61$ $\mathrm{J} \alpha, 67 \mathrm{~V} \beta, 14 \mathrm{~J} \beta, 2 \mathrm{D} \beta, 14 \mathrm{~V} \gamma, 5 \mathrm{~J} \gamma, 3 \mathrm{~V} \delta, 3 \mathrm{~J} \delta$ and $3 \mathrm{D} \delta$ segments. Roughly, $10^{7}$ Igs and TCRs can be generated by $\mathrm{V}(\mathrm{D}) \mathrm{J}$ recombination. In response to antigens, antigen receptors are further diversified by CSR and somatic hypermutation (SHM). In the following section, $\mathrm{V}(\mathrm{D}) \mathrm{J}$ recombination and CSR during $\mathrm{B}$ cell development will be reviewed.

B cell development begins in the fetal liver during development and continues in the bone marrow shortly after birth. It is a highly ordered process, mediated by cytokines secreted by bone marrow stromal cells and lineage-specific transcription factors. In response to cytokines such as IL-7, common lymphoid progenitors are committed to B cell lineage. Subsequently, cells undergo $\mathrm{D}_{\mathrm{H}^{-}} \mathrm{J}_{\mathrm{H}}$ joining at the Ig heavy chain locus and begin expressing CD45 (B220) and class II MHC (major histocompatibility complex), which is followed by the joining of a $\mathrm{V}$ segment to the completed $\mathrm{DJ}_{\mathrm{H}}$. After successful $\mathrm{V}(\mathrm{D}) \mathrm{J}$ recombination, pro-B cells become pre-B cells, which undergo V-J joining on one L chain locus and further develop into mature B cells. $\mathrm{V}(\mathrm{D}) \mathrm{J}$ recombination is regulated at three levels: chromatin remodelling, DSB generation mediated by lymphoid-specific recombinases (Rag-1/2) and recombination via NHEJ and microhomology-mediated end joining (MMEJ, also called alternative NHEJ) machinery.

In eukaryotic cells, DNA is wrapped into a compact chromatic structure, which needs to be 'opened' to allow accessibility for further processing. Increasing evidence in genetically modified mouse models shows that covalent histone modifications, such as methylation on histone $\mathrm{H3}$ at lysines 4, 9 and 27 (K4, K9 and K27) positions, mediate chromatin remodelling and subsequently $\mathrm{V}(\mathrm{D}) \mathrm{J}$ recombination. Enhancer of Zeste 2 (Ezh2) is a methyltransferase which trimethylates K27 of histone H3 (H3K27me3). Conditional deletion of Ezh2 in B lymphocytes leads to reduced H3K27me3 levels and defective $\mathrm{V}_{\mathrm{H}}-\mathrm{DJ} \mathrm{J}_{\mathrm{H}}$ recombination at the most distal V segments ( $\mathrm{Su}$ et al., 2003). Di- and tri-methylation of histone $\mathrm{H} 3 \mathrm{~K} 4$ are also found to be associated with the active segments in $\mathrm{V}(\mathrm{D}) \mathrm{J}$ recombination (Liu et al., 2007). Rag-2 binds to H3K4me3 via the PHD motif and mutations that abolish the interaction impair $\mathrm{V}(\mathrm{D}) \mathrm{J}$ recombination. In contrast, H3K9me2, a silent chromatin mark, inhibits distal $\mathrm{V}_{\mathrm{H}}-\mathrm{DJ} \mathrm{J}_{\mathrm{H}}$ recombination (Osipovich et al., 2004), while Pax5, a transcriptional factor required for early $\mathrm{B}$ cell commitment, regulates the removal of $\mathrm{H} 3 \mathrm{~K} 9 \mathrm{me} 2$ and promotes $\mathrm{V}_{\mathrm{H}}-\mathrm{DJ} \mathrm{H}$ recombination (Johnson et al., 2004). 
The coding sequences of $\operatorname{IgH}$ are separated by recombination signal sequences (RSSs). RSSs are conserved heptamers (CACTGTG) and nonamers (GGTTTTTGT) flanking either 12 base pairs (bp) or $23 \pm 1 \mathrm{bp}$ non-conserved DNA, called the spacer. The recombination of $\mathrm{D}_{\mathrm{H}}$ to $\mathrm{J}_{\mathrm{H}}, \mathrm{V}_{\mathrm{L}}$ to $\mathrm{J}_{\mathrm{L}}$ or $\mathrm{V}_{\mathrm{H}}$ to $\mathrm{DJ}_{\mathrm{H}}$ occurs only between the $12 \mathrm{bp}$ - and 23 bp-spacers, known as 12/23 spacer rule. Rag-1 and Rag-2 recognize RSSs and generate DSBs between the heptamers and its adjacent coding segment. Rag-1/2 first introduces a nick on one strand and then the nicked free coding end attacks the opposite strand, creating a closed hairpin structure. Disruption of either Rag-1 or Rag-2 in mice causes severely impaired V(D)J recombination, defective B cell development and immunodeficiency (Mombaerts et al., 1992; Shinkai et al., 1992).

The final step of V(D)J recombination involves NHEJ and MMEJ machineries where the two coding segments are ligated together. The proteins involved in NHEJ are not all known and new proteins are constantly being uncovered. Here, in this section we discuss those that are well-studied, including DNA-PK, Artemis endonuclease, and XLF (Xrcc4-like factor, also known as Cernunnos)-Xrcc4-DNA ligase IV complex. Deficiency in any of these proteins compromises B and/or T cell development. DNA-PK consists of catalytic subunit DNAPKcs and regulatory subunits Ku70 and Ku80. As mentioned earlier, DNA-PKcs phosphorylates H2AX at DSB to transduce signalling, while $\mathrm{Ku} 70$ and $\mathrm{Ku} 80$ form a heterodimer to process the broken ends. DNA-PKcs deficiency is the main cause of murine severe combined immunodeficiency (SCID), where both B and T cells are depleted (Blunt et al., 1995). Any defects in Ku protein also impair V(D)J recombination (Gu et al., 1997; Taccioli et al., 1993). Artemis is thought to open the closed hairpin at the coding ends generated by Rag-1/2. Null mutants of Artemis also give rise to the severe combined immunodeficiency (SCID) phenotype (Li et al., 2005). Xrcc4 together with XLF and DNA ligase IV ligates the broken ends together. Cells deficient for either Xrcc4, XLF or DNA ligase IV are sensitive to $\gamma$-irradiation and compromised in $\mathrm{V}(\mathrm{D}) \mathrm{J}$ recombination (Ahnesorg et al., 2006; Gao et al., 1998).

Upon antigen or humoral stimulation, CSR further diversifies antibodies by switching their isotypes. Human BCR heavy chain gene contains $9 \mathrm{C}_{\mathrm{H}}$ segments: $1 \mu(\operatorname{IgM}), 1 \delta(\operatorname{IgD}), 4 \gamma$ $(\operatorname{IgG}), 1 \varepsilon(\operatorname{IgE})$ and $2 \alpha(\operatorname{IgA})$. CSR occurs between two switch (S) regions located upstream of each $\mathrm{C}_{\mathrm{H}}$ segment, except for $\mathrm{C} \delta$; the switch between $\mathrm{C} \mu(\operatorname{IgM})$ and $\mathrm{C} \delta(\operatorname{IgD})$ is achieved by alternate splicing before complete maturation of B cells. Similar to V(D)J recombination, CSR also involves DSB generation and NHEJ. DSBs are created by $\mathrm{dC}$ deamination, BER and MMR machinery within or near $S$ regions. In response to humoral stimulation, activationinduced cytidine deaminase (AID) deaminates $\mathrm{dC}$ resulting in dU bases on both strands of two transcriptionally active $S$ regions (Chaudhuri et al., 2003). The $\mathrm{dU}$ is excised by the uracil DNA glycosylases (UNG) and the resultant abasic site is further cut by apurinic/apyrimidinic endonuclease 1/2 (APE-1/2), generating SSBs. Either two adjacent SSBs on opposite strands spontaneously lead to one DSB, or the MMR machinery is triggered to convert SSB to DSB (Schrader et al., 2007). Deficiency of AID, UNG, APE or any of the MMR components, including Msh2, Msh6, Mlh1, Pms2 and Exo1, leads to loss or reduction of CSR in B cells (Stavnezer et al., 2008). After DSB formation, NHEJ rather than HR pathway is activated. Components of classical NHEJ (C-NHEJ) pathway are important but not essential for CSR in B cells. Ku70-Ku80 heterodimers bind to the DNA ends and recruit necessary proteins to process the DNA ends to facilitate the ligation mediated by Xrcc4-DNA ligase IV complex (Nick McElhinny et al., 2000). CSR in $\mathrm{Ku}^{-1} 0^{-/}$and $\mathrm{Ku} 80^{-/-} \mathrm{B}$ cells is nearly ablated (Casellas et al., 1998; Manis et al., 1998). Either Xrcc4 or DNA ligase IV 
deficiency causes significant reduction in CSR (Soulas-Sprauel et al., 2007; Yan et al., 2007). While compatible ends are joined rapidly by canonical NHEJ components, complex lesions need substantial processing and are re-ligated slowly. In the later case, ATM, 53BP1 and MRM complex cooperate with canonical NHEJ components to mediate end-joining recombination. Disruption of ATM (Bredemeyer et al., 2006; Reina-San-Martin et al., 2004), 53BP1 (Manis et al., 2004) or MRN complex (Kracker et al., 2005) in mice leads to defects in either V(D)J recombination or CSR or both. Recent studies in mouse models deficient for NHEJ core components revealed a robust alternative NHEJ pathway (A-NHEJ) that utilizes microhomology to mediate the end joining in CSR (Soulas-Sprauel et al., 2007; Yan et al., 2007). A-NHEJ leads to Ig locus deletion and translocation. The molecular mechanisms underlying A-NHEJ are not well elucidated so far.

\subsection{Meiosis}

Meiosis is a form of cell division occurring in sexually reproducing organisms by which maternal and paternal chromosomes are distributed between cells to generate genetic diversity. Prior to meiosis, each chromosome duplicates and creates two sister chromatids, which stay connected at the centromere. During meiosis, the homologous chromosomes align in parallel and chromosomal crossovers are induced by recombination. DSBs are generated by meiosis-specific topoisomerase-like enzyme Spo11 (Keeney et al., 1997), together with Mei1. Mice lacking Spo11 or Mei1 fail in the generation of DSBs, leading to absence of Rad51 foci, faulty synapsis, meiotic failure and eventually infertility (Baudat et al., 2000; Libby et al., 2003; Munroe et al., 2000; Romanienko and Camerini-Otero, 2000). The generation of DSB on meiotic chromosomes is not entirely random but occurs preferentially on specific chromosomal locations, known as hot spots. Recombination regulator 1 (RCR1) and double strand break control 1 (DSBC1) regulate the activities of recombination hot spots (Grey et al., 2009; Parvanov et al., 2009). Although the molecular mechanisms underlying the selection of hot spots for DSB induction are still under investigation, it has been found that high-order chromatin structure could be an important factor (Buard et al., 2009). Of particular interest is the methylation of histone H3K4me3 by the methyltransferase Prdm9 (also known as Meisetz), which is enriched at meiotic recombination hot spots (Baudat et al., 2010; Borde et al., 2009; Buard et al., 2009). Prdm9 null mice are sterile owing to defective chromosome paring and impaired sex body formation (Hayashi et al., 2005; Mihola et al., 2009).

Many components of the HR pathway are of particular importance for proper strand exchange and meiosis. As mentioned earlier, MRN complex is recruited to the DSBs to remove Spo11 and degrade the $5^{\prime}$ of DNA, generating long $3^{\prime}$ ssDNA overhangs. ATM is activated by MRN and further amplifies the signaling via phosphorylation of many downstream transducers and effectors, such as H2AX and Chk2 (Shiloh, 2003). Finally, ubiquitously expressed Rad51 and meiosis-specific Dmc1 recognize and bind to the resected 3' ssDNA overhangs and form nucleoprotein filaments, which mediate the search for homologous template and subsequent strand exchange. As they are all essential for development, disruption of either Rad51 or any component of MRN complex causes embryonic lethality (Buis et al., 2008; Luo et al., 1999; Zhu et al., 2001). Loss of ATM in mice causes general defects in DSB repair and mislocalization of Rad51 and Dmc1 in spermatocytes (Barlow et al., 1996; Barlow et al., 1998). During meiosis, Dmc1-/- germ cells arrest at the early zygotene stage due to the failure of homologous chromosome synapsis (Yoshida et al., 1998). 
In contrast to mitotic recombination in which Rad51-mediated HR utilizes the identical sister chromatid as homologous template (reviewed earlier in Section 2.6), Rad51 and Dmc1mediated strand invasion prefers the chromatids from the homologous chromosome in meiotic recombination. This preference is achieved with the help of other factors such as chromosome-associated kinase Mek1, which excludes identical sister chromatid from being selected as a homologous template for further meiotic recombination. As a byproduct, this generates a heteroduplex DNA (hDNA) if there are heterologies between the two homologous chromosomes (maternal and paternal). In this case, MMR pathway is activated to repair the hDNA, resulting in either gene conversion (GC) or restoration of original sequences (Kramer et al., 1989). Two recombination pathways are employed, i.e. cross-over (CO) and non-cross-over (NCO). CO occurs when double Holiday junctions (dHJs), which are visualized as chiasmata, are formed and subsequently cut by resolvases. NCO is also known as synthesis-dependent strand annealing (SDSA), leading to gene conversion. MMR pathways are not only restricted to resolving hDNA because $M l h 1^{-/-}$mice exhibit defective gametogenesis due to reduction of chiasmata, recombination and COs, and deficiency in Pms2 leads to disrupted synapsis (Baker et al., 1995; Baker et al., 1996; Edelmann et al., 1996). Msh4 and Msh5 are two meiosis-specific homologues of MutS, which interact with Rad51 to stabilize the synaptonemal complex (SC) mediated chromosome paring. Targeted mutations of Msh4 and Msh5 in mice give rise to meiotic-specific phenotypes, including meiotic arrest at zygotene stage and defective synapsis (de Vries et al., 1999; Edelmann et al., 1999; Kneitz et al., 2000). Mlh3 and Exo1 null mice are also infertile, attributed to meiotic failure and apoptosis (Lipkin et al., 2002; Wei et al., 2003).

\subsection{DNA damage signaling in stem cells}

Recently, it has become apparent that tissue stem cells possess an elaborate DDR to maintain organ homeostasis, although the mechanistic details seem to vary greatly between different tissues. The DDR in response to radiation exposure has been studied in detail in at least four adult stem cell types: epidermal stem cells, hematopoietic stem cells, mammary stem cells and intestinal stem cells. By comparing the response of haematopoietic stem cells (HSCs) with their differentiated progeny at low doses of IR, it has become clear that different DNA repair and signalling mechanisms exist within the stem cell compartment. Using fetal human umbilical cord blood derived HSCs and by comparing them with their more mature progenitors, it was found that stem cells had greater level of apoptosis, due to the ASPP1 protein, and the phenotype could be rescued by the down regulation of p53 (Milyavsky et al., 2010). In contrast, when a similar experiment was performed using adult mouse HSCs, low doses of IR showed a greater degree of protection in stem cells as compared to their differentiated counterparts. The underlying mechanism was proposed to be the increased expression of anti-apoptotic Bcl2, Bcl-xl which inhibited p53-mediated cell death, while allowing p53-dependent increase in p21 expression (Mohrin et al., 2010). Interestingly, quiescent HSCs mostly preferred NHEJ pathway for DNA repair, and as a consequence their progeny often showed increased levels of genomic instability due to misrepaired DNA. Recent investigations using multipotent hair follicle bulge stem cells (BSC) also revealed that BSCs were more resistant to DNA damage-induced cell death as compared to other cells of the epidermis (Blanpain and Fuchs, 2009). The underlying mechanism was shown to be the increased expression levels of anti-apoptotic $\mathrm{Bcl} 2$ and the transient and reduced duration of 
p53 up regulation. BSCs also displayed accelerated repair by the error-prone NHEJ pathway and this result suggested that both HSCs and BSCs show short term survival in the wake of DNA damage at the expense of a compromise on their genomic integrity.

Irradiation experiments have also been performed on intestinal stem cells (ISC) to understand their DDR. The intestinal stem cells are localized at the bottom of the crypt, where they proliferate and generate the transit amplifying cells, which divide and migrate to the upper part of the crypt. At least two distinct stem cell populations have been isolated from the intestine corresponding to the +4 position from the bottom of the crypt, which are positive for the stem cell marker Bmi1+ and quiescent and the cycling Lgr5+ fraction located in between the paneth cells at the base of the intestinal crypt (Barker et al., 2010). Radiation sensitivity experiments have revealed that the quiescent stem cells at the +4 position are extremely radiosensitive, followed by the more active Lgr5+ve cells, whereas the rapidly cycling transit amplifying cells were the most radioresistant. Different mechanisms have been proposed for the extreme sensitivity of the Bmi1+ve ISCs to DNA damage, such as enhanced activation of the p53 pathway, lower expression of anti-apoptotic protein Bcl2. However, based on the observation that IR-induced stem cell apoptosis is blocked in PUMA-deficient mice, it is accepted that Puma is the main mediator of DDR in ISCs (Qiu et al., 2008). The DDR has also been studied in germ stem cells (GSC) since the inability to repair DNA damage in the germ line can be extremely dangerous and can directly lead to infertility or the transmission of genetic diseases. The main source of DNA damage in the germ-line could be from teratogenic chemicals or from normal metabolic activity and ROS production. In studies using human male GSCs, it was found that these cells are mostly kept in the G0/G1 phase of the cell cycle, and preferentially use NHEJ as their repair of choice. On the other hand, the female GSCs are located in the oogonia where the homologous chromosomes are close to each other and hence HR is the preferred pathway for DNA repair (Forand et al., 2009). Interestingly, in contrast to other stem cell populations, the female GSCs do not depend on p53 for their genomic integrity. Instead, TAp63, an isoform of the p63 gene, is constitutively expressed in oocytes and is the primary mediator of DDR. Consistently, TAp63 deletion in mice results in an increase in oocyte radioresistance (Suh et al., 2006). The study of DNA repair in another stem cell type, namely the mammary stem cells (MSCs), is clinically very relevant because, mutations in Brca1 and Brca2 are found in a majority of patients with hereditary breast cancers, demonstrating the importance of HR in preventing the onset of mammary tumors. The MSCs are responsible for the homeostasis of the breast tissue, and represent multipotent stem cells that self-renew and differentiate into the various lineages. Mouse MSCs are more radioresistant than their differentiated progeny. MSCs present less DNA damage and following IR exposure, activate the Wnt/beta-catenin pathway and increase the survival of MSCs through the upregulation of survivin, a direct Wnt target gene (Woodward et al., 2007).

\section{DNA damage response and human diseases}

Congenital or acquired defects in genes involved in the DDR give rise to disease phenotypes such as neurodegeneration, infertility, immune deficiencies, growth retardation, cancer and premature aging. In the following sections, human diseases caused due to impaired DDR are described in greater detail and summarized in Figure 3 and Table 1. 


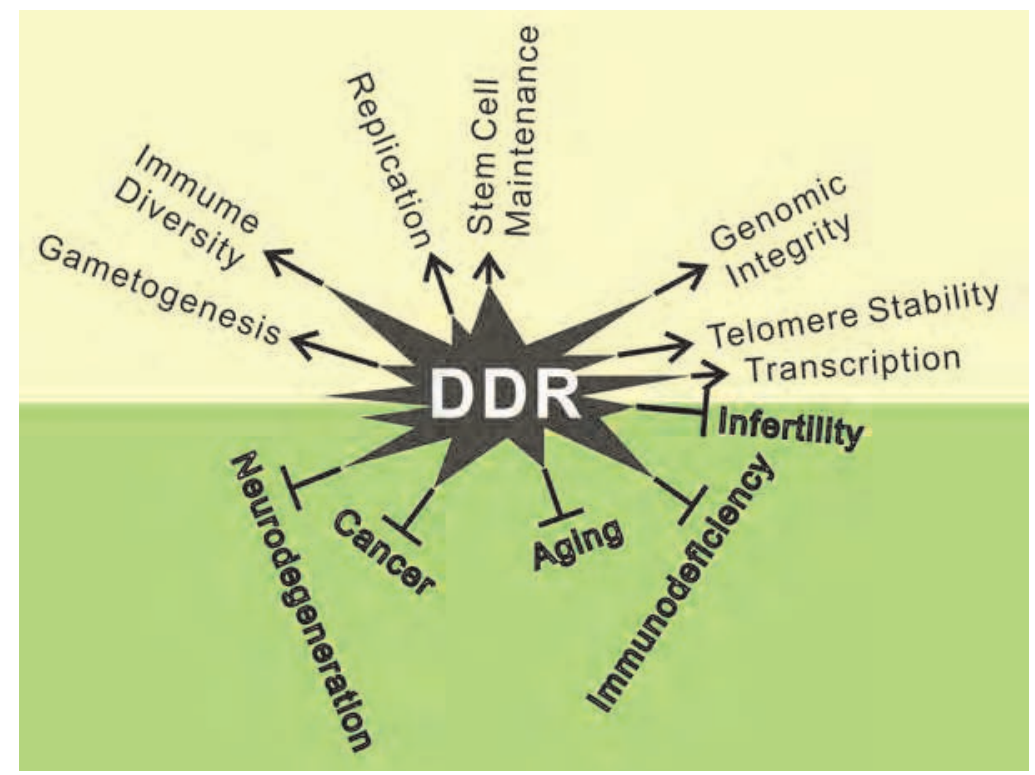

Fig. 3. Physiological roles of DDR and disease phenotypes caused by defective DNA repair

\subsection{Neurodegeneration}

The mammalian nervous system is generated through consecutive cycles of proliferation, differentiation and maturation that eventually give rise to the various cell types of the brain. Two main classes of cells make up the nervous system: the glia and the neurons, and these contain many specialized sub-types. These cells exit the cell cycle, migrate and differentiate to form the nervous system. In general, neurons display high rates of transcription and translation which are associated with high rates of mitochondrial and metabolic activity. Thus, the neural cells are more susceptible to DNA damage than other adult tissue cell types because they face high levels of oxidative and metabolic stress during their life time. The DNA damage takes the form of both SSBs and DSBs that have to be efficiently repaired to maintain neural homeostasis. Indeed, one of the most commonly observed symptoms in both DNA repair-deficient mice and in humans is that of neurodegeneration. This is mainly because individuals possessing mutations in DNA repair pathways are incapable of handling DNA damage in the neurons, resulting in neuronal cell death that is manifested as neurodegeneration (Katyal and McKinnon, 2008).

The DNA strand breaks in the nervous system may arise due to reactive oxygen species (ROS) that arise as a by-product of cellular metabolism. ROS, in turn carries out nucleophilic attack on DNA to generate single strand breaks. Due to the high levels of oxygen consumption in the brain, ROS levels are very high in the neurons compared to other adult cell types. In fact, tens to thousands of SSBs are generated by ROS in neuronal cells, and these constitute the single largest source of DNA damage in the nervous system (Katyal and McKinnon, 2008). As discussed earlier (Section 3.1), SSBs are efficiently detected by PARP which recruits the scaffolding protein XRCC1 so that the DNA lesions can be resolved by enzymes involved in DNA processing. Unrepaired SSBs can cause a block in transcription, or replication forks can collide with SSBs resulting in DSBs that have to be then repaired by the DSB repair pathway. 
Human monogenic neurodegenerative defects associated with DDR defects can be broadly classified as those associated with DSB repair or SSB repair. Defective DSB repair associated neuropathologies include A-T, Nijmegen breakage syndrome (NBS), ATLD (A-T like disorder), Seckel syndrome, Primary microcephaly (PM), and the Lig4 syndrome. In most DNA repair-associated syndromes, cerebellum is often the primary target of neurodegeneration which then spreads to the remaining parts of the brain. A-T syndrome arises as a result of mutations in ATM. Since cerebellum is mainly responsible for sensory motor coordination, individuals with A-T often present with profound ataxia (defective motor coordination) and are wheelchair-bound within the first decade of life. The DDR pathway in A-T strongly affects the cerebellum and widespread loss of cerebellar purkinje cells and granule neurons is seen in A-T brains and is later accompanied by widespread cerebral and spinal defects. Additionally, A-T patients develop other neurological defects such as defective eye movement, speech defects (dysarthria) and non-neurological symptoms such as the absence or the rudimentary appearance of a thymus, immunodeficiency, insulin-resistant diabetes, clinical and cellular radiosensitivity, cell cycle checkpoint defects, chromosomal instability and predisposition to lymphoid malignancies (Biton et al., 2008). Because of the central role of the MRN complex in the ATM-dependent DDR, human syndromes caused by defects in the MRN complex have been regarded as ATlike disorders. Very similar to AT, NBS is characterized by growth retardation, frequent infections, microcephaly (described below), ovarian dysgenesis (defective development), primary amenorrhoea and lymphoma predisposition. However, NBS cells also appear to be defective in some aspects of the ATR pathway and exhibit phenotypes like microcephaly (described below), not usually seen in A-T patients. Patients suffering from ATLD (A-T like disorder) have hypomorphic mutations of MRE11 and show neurological symptoms very similar to A-T such as dysarthria, oculomotor apraxia and ataxia. Interestingly, a cancer predisposition phenotype has not been observed with ATLD. Also, in contrast to NBS patients, ATLD subjects do not have microcephaly (Katyal and McKinnon, 2008).

In addition to neurodegeneration, defective DSB repair can cause developmental defects in the brain, resulting in the development of a smaller brain, called microcephaly where the brain size is at least two standard deviations smaller than the normal brain. This phenotype probably arises as a result of brain cell loss due to the inability to cope with DNA damage in the developing brain. For example, patients harbouring germ-line mutations in ATR, suffer from the Seckel syndrome, an autosomal recessive disorder characterized by severe intrauterine growth retardation, profound microcephaly, a 'bird-like' facial profile, mental retardation and isolated skeletal abnormalities (O'Driscoll et al., 2009). Patients harbouring mutations in the centrosomal protein pericentrin also show pronounced microcephaly as a result of DNA replication fork defects and defective DNA repair. Patients bearing hypomorphic mutations in Lig4, the DNA ligase in the NHEJ pathway also present with microcephaly, developmental and growth delay, immunodeficiency and lymphoid malignancies. Mutation in another NHEJ protein XLF, causes a disorder called as HIM (Human immunodeficiency and microcephaly), primarily characterised by growth delay, recurrent infections, autoimmunity and microcephaly (Katyal and McKinnon, 2008).

Unlike defective DSB pathway, where the associated defects are more wide spread across tissues, defective SSB repair pathway often results in phenotypes restricted to the nervous system. For example, defective SSB repair pathway result in spinocerebellar ataxia and axonal neuropathy (SCAN1) and ataxia with oculomotor apraxia (AOA1), which are caused 
by mutations in the $3^{\prime}$-endprocessing enzyme tyrosyl DNA phosphodiesterase 1 (TDP1) and the 5 '-end-processing enzyme aprataxin (APTX), respectively (McKinnon, 2009). As mentioned earlier, TDP1 is an enzyme involved in the processing of damaged DNA ends, such as 3'-phosphoglycolate and 3' Top1 and other non-ligatable termini generated after DNA oxidation, DNA replication and other types of genotoxic stress. APTX, on the other hand, is a nucleotide hydrolase that cleaves the $5^{\prime}$ adenylate intermediate prior to sealing the nick after the generation of SSB. Similar to A-T patients, SCAN1 and AOA1 patients show ataxia, oculomotor apraxia, cerebellar atrophy and dysarthria. Cockayne's syndrome and $\mathrm{XP} / \mathrm{CS}$ are associated with defects in CSA, CSB, XPB, XPD and is associated with neurological symptoms such as microcephaly, progressive neurodegeneration, cerebral and cerebellar atrophy and sensorineural deafness (Weidenheim et al., 2009). In another SSRassociated syndrome called as trichothiodystrophy (TTD), the proteins XPB, XPD, TTDA are found defective (Stefanini et al., 2010). This syndrome is associated with cerebral cortex microcephaly, hypomyelination and psychomotoric abnormalities.

Recent studies have also highlighted the role of defective DNA repair in late-onset chronic neuropathologies such as Alzheimer's disease and Parkinson's disease. For instance, decreased levels of NHEJ factor DNA-PKcs and of MRN proteins and reduced BER capacity has been documented in Alzheimer's disease patients, whereas increased DNA damage accumulation has been observed in the substantia nigra neurons, a population of neurons often depleted in Parkinson's disease patients (Katyal and McKinnon, 2008).

\subsection{Infertility}

Human infertility is primarily defined as the inability to conceive after 12 months' intercourse and is often underdiagnosed (Thonneau et al., 1991). However the investigation of human infertility is hampered by the fact that defective meiotic recombination usually leads to either germ cell arrest or abnormal gametes. Some candidate genes such as PRDM9 and MEI1 have been found to contain mutations/polymorphisms in patients suffering from infertility (Miyamoto et al., 2008; Sato et al., 2006). MSH4 and DMC1 mutations have also been found in patients suffering from testis vanishing syndrome and premature ovarian failure (Mandon-Pepin et al., 2002).

\subsection{Immune deficiency}

As reviewed earlier in this chapter (Section 4.1), NHEJ machinery is used for V(D)J recombination, CSR and SHM in order to generate antigen receptor diversity. Defects in DSB generation and NHEJ components usually compromise V(D)J recombination, CSR and/or SHM, thereby leading to primary inherited immunodeficiency. Severe combined immunodeficiency (SCID) is a severe form of inheritable immunodeficiency. In SCID, both B and $\mathrm{T}$ adaptive immune systems are impaired and the patients are extremely vulnerable to various infectious diseases. Defects in V(D)J recombination usually lead to SCID in humans because it is required for both $B$ and $T$ antigen receptor generation. During $V(D) J$ recombination, RAG-1 and RAG-2 are responsible for DSB generation and mutations of either of them in humans are reported in some cases of SCID (Schwarz et al., 1996; Villa et al., 1998; Villa et al., 2001). Recently the first missense mutation of DNA-PKcs was reported in a human patient suffering from pronounced immunodeficiency. Strikingly, the mutation doesn't affect the kinase activity of DNA-PKcs but rather compromises the activity of Artemis (van der Burg et al., 2009). After DSB generation, Artemis processes the hairpin 
intermediates for end-joining. Mutations in Artermis arrest B and T cells at very early stage in some cases of SCID, owing to the defective V(D)J recombination (Ege et al., 2005; Moshous et al., 2001). Hypomorphic mutations of DNA ligase IV have been identified in individuals with SCID or combined immunodeficiency (CID) displaying microcephaly and delayed growth (Enders et al., 2006; O'Driscoll et al., 2001; Riballo et al., 1999; van der Burg et al., 2006). Similarly, patients with XLF mutations develop severe B-T lymphocytopenia, microcephaly and growth retardation (Ahnesorg et al., 2006; Buck et al., 2006).

In addition to the essential components of $\mathrm{V}(\mathrm{D}) \mathrm{J}$ recombination, mutations in other DSB repair factors also cause a less profound immunodeficiency characterized by defective lymphocyte development and IgG CSR defects. As described earlier (Section 5.1), Ataxia telangiectasia (AT) is a progressive genetic disorder caused by mutated ATM and is characterized with cerebellar ataxia, oculocutaneous telangiectasia, growth retardation, infertility, immunodeficiency and increased carcinogenesis mainly lymphoid tumours (Chun and Gatti, 2004). In AT patients, V(D)J recombination is not affected, but both B and T lymphocytes are restricted and skewed by diffused oligoclonal expansions (Giovannetti et al., 2002). While dispensable for SHM, ATM-deficient cells are compromised in diversifying IgM to other classes (Reina-San-Martin et al., 2004). Immunodeficiency is also manifested in NBS patients who are found more susceptible to infectious diseases (Digweed and Sperling, 2004). Similar to ATM, deficiency of either NBS1 or MRE11 doesn't affect normal V(D)J recombination although CSR is impaired (Lahdesmaki et al., 2004; van Engelen et al., 2001).

\subsection{Cancer}

Loss of genomic integrity and accumulation of mutations is a fundamental property of cancerous cells. In that context, the DDR influences cancer progression in multiple ways, as discussed below.

\subsubsection{DNA repair defect and familial cancers}

The concept that cancers could be acquired by DNA repair defects was first obtained by the study of patients suffering from familial hereditary cancers. Xeroderma pigmentosa (XP) was one of the first of many human cancers discovered to be acquired due to defective DNA repair (Cleaver, 2005). XP patients are defective in the NER of UV-induced DNA damage and have a 1000-fold greater risk of developing skin cancers and a 100,000 fold greater risk for developing squamous cell carcinoma of the tip of the tongue when compared to the general population. HNPCC (Hereditary non-polyposis colon cancer, also called as Lynch syndrome) is another inherited cancer syndrome where patients show an increased susceptibility to colon cancers. While the adenoma to carcinoma progression requires 8-10 years in the general population, this process is accelerated to 2-3 years in HNPCC patients. The majority of HNPCC cases result from germ-line mutations in genes encoding for the MMR proteins MSH2 and MLH1 (Fishel et al., 1993; Leach et al., 1993). Mutations in two other MMR genes MSH6 and PMS2 were also detected in a small proportion of cases. The resulting inability to detect and repair mismatches can lead to mutations of genes possessing microsatellite repeats in their sequences, causing a phenotype referred to as microsatellite instability. In addition to hereditary cases, MMR defects have also been detected in about $15 \%$ of sporadic gastric, endometrial and colon tumors owing to promoter hypermethylation and the consequent silencing of MLH1. In many of the tumors showing MMR defects and microsatellite instability, it is likely that hundreds of genes are 
concomitantly mutated and some of them such as the commonly studied type II TGF- $\beta$ receptor may confer a proliferative advantage to incipient cancer cells and drive tumor progression. Another example is hereditary MYH-associated polyposis, in which biallelic germ-line mutations in $M Y H$, a BER gene, result in increased GC to TA transversion and predisposition to colon cancer (Al-Tassan et al., 2002). Defective DSB repair attributed to germ-line transmission of mutant BRCA1 and BRCA2 alleles also confer enhanced susceptibility to breast and ovarian cancers. It is estimated that about $70-80 \%$ of all familial ovarian cancers is due to germ-line transmission of BRCA1 or BRCA2 (Scully and Livingston, 2000). Germ-line mutations in DNA repair genes NBS1, ATM, Werner syndrome helicase $(W R N)$, Bloom syndrome helicase (BLM), RecQ protein-like 4 helicase (RECQL4) has also been linked to increased tumor susceptibility. Mutations in $p 53$ are present in cancerprone families with Li-Fraumeni syndrome (Brown et al., 2009). As discussed in section 2.5, mutations in 14 FANC genes have been identified in Fanconi anaemia, which is an autosomal recessive hereditary disorder characterized by progressive bone marrow failure, congenital developmental abnormalities, and early onset of cancers such as acute myelogenous leukemia (AML) and squamous cell carcinomas of the head and neck. Together, these observations support the 'mutator hypothesis' which postulates that inherited defects in DDR contribute to the 'mutator' phenotype and increased mutation rate in many malignancies which might allow tumor cell survival and proliferation.

\subsubsection{DDR and sporadic cancers}

Apart from inherited mutations in proteins involved in DNA repair, recent large scale genome sequencing of cancer genomes have also identified mutational inactivation of components of the DDR machinery in sporadic cancers. Of these, mutations that perturb p53 functions, often in its DNA binding domain, or defects in p53's upstream or downstream regulatory network have been identified in more than half of all human cancer samples. Recently, coding sequences of about 20,000 genes in carcinomas of the colon, breast, pancreas and glioblastomas were sequenced. In these sequencing studies representing 68 cancers in the discovery screen and 221 cancers in the follow-up validation screen, one of the most frequently mutated gene was Cockayne syndrome B (CSB), found mutated in 6 cancers (Sequencing data compiled by Negrini et al, 2010 (Negrini et al., 2010)). Four genes involved in the DSB repair pathway, BRCA1, BRCA2, MRE11 and PRDKC (gene encoding DNA-PKcs) were each mutated in two cancers and one mutation each in the genes encoding FANCA, FANCG and FANCM, PABL2, WRN, XRCC 1, XPB, XPF. XPG, RAD23A was identified. In a more controlled study involving the analysis of a limited set of DNA repair and cell cycle checkpoint genes in 188 lung adenocarcinomas and 91 glioblastomas, the NHEJ mutation in PRDKC and mismatch repair gene $M S H 6$ were each mutated in six and four cases respectively. The HR repair genes $B R C A 2, B A P 1$ and $B A R D 1$ were mutated in two cases each. Mutations in ATM were also identified in a few cases of lung adenocarcinomas. Notably, although large scale genome sequencing projects identified mutations in the genes involved in DNA repair, such mutations were detected only in a small proportion of human cancers (Negrini et al., 2010).

\subsubsection{DDR and oncogene-induced senescence}

An alternative model has been proposed that postulates that DDR, in fact, acts as a barrier to cellular transformation in the early stages of tumor progression by preventing the 
accumulation of mutations in the face of activated oncogenes (Bartek et al., 2007). According to this idea, the first hallmark to be acquired in sporadic cancer might be activated growth factor signalling owing to mutations in oncogenes and loss of tumor suppressor genes (Negrini et al., 2010). This results in an increased cell proliferation rate which generates a DNA replication stress, as shown for several oncogenes like Ras, Myc, Stat3 and E2FF1 (Bartkova et al., 2006). DNA replication stress, in turn, creates a high level of DNA damage, which results in the persistent activation of the DDR in the form of activated ATM/ATR signalling cascade causing cell death or senescence of incipient cancer cells. The senescence pathway evoked by oncogenes upon hyper-activation is now commonly referred to as the oncogene-induced senescence and is recognised as an important barrier to tumor progression (Gorgoulis and Halazonetis, 2010). Consistent with this idea, human lung, skin and colon precancerous lesions, show both apoptosis and senescence at the early stages of tumor development, whereas these processes are actively suppressed during cancer progression. Endogenous oncogenic K-Ras (K-Ras G12V) was shown to trigger senescence during the early stages of lung and pancreatic tumorigenesis. Melanocyte senescence has also been associated with the presence of oncogenic BRAFV60E, an oncogenic form of BRAF, in vivo (Michaloglou et al., 2005). Similarly, human prostate intraepithelial neoplasia (PIN) lesions and premalignant human colon adenomas display features of cellular senescence. Loss of the tumor suppressor neurofibromin 1 (NF 1), a Ras GTPase-activating protein that negatively regulates Ras, also leads to cellular senescence. By sharp contrast, senescence was absent in the corresponding malignant stages of human lung adenocarcinomas, pancreatic ductal adenocarcinomas, prostate adenocarcinoma and melanomas, suggesting that senescence acts as a barrier to tumor development. It is proposed that breaches to this anticancer barrier, arising due to mutational or epigenetic inactivation of DDR components help in the evasion of senescence and are subsequently selected for during tumor development.

\subsubsection{DDR in cancer stem cells}

Gaining a better understanding of the role of DDR in cancer cells is also important from a stand point of therapy, since most chemotherapeutic compounds are DNA damaging agents. Many human cancers including leukemia, glioblastoma, breast and skin cancers contain a small proportion of cells which are functionally similar to tissue-stem cells, but have aberrant self-renewal and differentiation characteristics and these have been called as cancer stem cells (CSCs) (Clarke and Fuller, 2006). Recent studies have suggested that CSCs are responsible for disease progression and tumor relapse after therapy, since they may take advantage of the DNA repair systems used by tissue-stem cells to achieve resistance to chemotherapy/radiotherapy (Blanpain et al., 2011). Here, we discuss three instances where the DDR has been demonstrated to have an effect on the outcome of cancer therapy. In the first case, the CSCs of leukemias, which exist in both acute myeloid leukemia (AML) and chronic myelogenous leukemia (CML) have been shown to be more resistant to cancer therapies as compared to the bulk of the leukemia cells. Leukemia CSCs have been shown to use protective mechanisms similar to HSCs, such as cell cycle quiescence, and DDR mechanisms to escape chemotherapy. For example, p53-dependent induction of p21 and the resulting growth arrest has been found to be critical in protecting adult HSCs from IR (Mohrin et al., 2010) and CSCs from leukemia co-opt similar protective mechanisms to evade apoptosis and during chemotherapy (Viale et al., 2009). There is also evidence that CSCs isolated from breast cancers (CD44 high, CD24 low cells) show resistance to chemo/and or radiotherapy. Transcriptional profiling of murine mammary CSCs also 
showed increased expression of several DDR and DNA repair genes (Zhang et al., 2008), suggesting that mammary gland CSCs may also be more resistant to therapy. Indeed, a comparison of tumor biopsies before and after neoadjuvant chemotherapy showed increased proportion of CSCs following chemotherapy. One possible mechanism seems to be that like normal mammary stem cells, CSCs from mammary gland have increased levels of genes regulating free radical scavenging systems, like those of glutathione metabolism (Diehn et al., 2009). Lastly, glioblastoma multiforme (GBM) represents the most aggressive form of brain tumor and CSCs are isolated from these tumors based on the expression of prominin (CD133-positive cells). Upon irradiation, the proportion of CD133+ cells increased, suggesting that CSCs may be responsible for tumor relapse after radiotherapy (Bao et al., 2006). It was found that CSCs from GBM exhibited a more robust activation of DNA damage checkpoint and increased phosphorylation of ATM, Chk1 and Chk2 were observed in the CSCs as compared to the non-CSC counterparts. Consistently, treatment with Chk1/Chk2 inhibitors sensitized the CSC to IR-induced cell death.

\section{DNA repair and aging}

Aging involves a gradual deterioration of several physiological functions, resulting in the reduced capacity to repair injured organs, increased propensity to infections, cancer predisposition and decreased fecundity (DiGiovanna, 2000; Partridge and Mangel, 1999). Many hypotheses have been proposed to understand the underlying mechanisms of the aging process, and these include the disease theory, free radical theory and DNA damage accumulation theory. In this section, we only discuss evidences that support the relationship between DNA damage accumulation and aging, a concept proposed more than half century ago by Leo Szilard (Szilard, 1959). Throughout the life-span, cells are constantly exposed to different endogenous or exogenous conditions that lead to DNA lesions which trigger DNA damage checkpoint response and DNA repair signalling. The accumulation of unrepaired/unrepairable DNA damage within cells leads to a sustained DNA damage checkpoint response and induces a state called cellular senescence, wherein cells permanently exit from the cell cycle. Consistent with this idea, it has been documented that DNA damage in the form of DSB-specific foci containing $\gamma-\mathrm{H} 2 \mathrm{AX}$ accumulate in senescent human cells, germ and somatic cells of aged mice, and in dermal fibroblasts from aged primates (Maslov and Vijg, 2009). Mouse models harbouring deficiency in DNA repair proteins, such as ATM, Ku70, Ku80, DNA ligase IV or Ercc1 also show premature aging phenotypes, providing evidence of a direct correlation between impaired DDR and premature aging (Hasty, 2005; Hoeijmakers, 2009).

So far, the relationship between DNA damage accumulation and aging has gained maximum credibility through studies conducted on various human progeria syndromes. Progeria syndromes are genetic disorders where patients precociously develop features resembling natural aging. Interestingly, most of the reported progeria syndromes, including Werner syndrome (WS), Bloom's syndrome (BS), Rothmund-Thomson syndrome (RTS), Cockayne syndrome type A and type B (CSA and CSB), Xeroderma pigmentosum (XP), Trichothiodystrophy (TTD) and Hutchinson-Gilford progeria syndrome (HGPS) were caused by mutations of genes that were directly or indirectly involved in DNA repair pathways. WS, BS and RTS are associated with defects in RecQ helicases, i.e. RECQL2 (WRN), RECQL3 (BLM) and RECQL4 respectively, whereas CS, XP and TTD shared similar defects in NER pathway. RecQ helicases are a group of highly conserved proteins from 
bacteria to humans. The roles of RecQ helicases in DNA metabolism, including DNA replication (Lebel et al., 1999), transcription (Balajee et al., 1999), repair (Cooper et al., 2000; $\mathrm{Li}$ and Comai, 2000) and recombination, have been extensively investigated and are demonstrated to be the underlying pathological basis of WS, BS and RTS. Most recently, delayed DNA damage checkpoint response and defective DNA repair were found to contribute to the progeria phenotypes in HGPS as well (Liu et al., 2005).

Since WS closely resembles physiological aging, WS cells have been the subject of intense investigation to understand the biology and molecular mechanism of normal aging. WS is an autosomal recessive genetic disorder of "progeria in adulthood", affecting about 10 in one million (Multani and Chang, 2007). Patients suffering from WS are usually born healthy, with obvious growth retardation from the second decade and other ageing-related features, including short stature, premature cataract, beaked nose, skin atrophy and alopecia, loss of adipose tissues, type II diabetes, osteoporosis, arteriosclerosis, hypogonadism and predisposition to cancer. WS patients typically die of early onset cardiovascular diseases or neoplasia in the fourth decade of life and have an average life expectancy of 47 years. Skin fibroblasts cultured from affected individuals develop accelerated senescence with increased chromosome aberrations (Melcher et al., 2000; Salk et al., 1981). By positional cloning, WRN was firstly linked to WS (Yu et al., 1996). Before the identification of LMNA mutations (see below) in atypical WS, WRN was the only protein implicated in WS. WRN belongs to the family of RecQ helicases, and is the only member with a specific exonuclease domain within the N-terminus (Gray et al., 1997; Huang et al., 1998). Physiological and functional interactions between WRN and other proteins suggest that it has crucial roles in DNA replication and repair. WRN interacts with proteins required for DNA replication, such as RPA (Brosh et al., 1999), PCNA (Lebel et al., 1999), FEN1 (Brosh et al., 2001) and DNA polymerase (Polס) (Kamath-Loeb et al., 2001). Studies from Lebel and colleagues (1999) indicated that WRN was involved in restoration of stalled replication forks. WRN also interacts with heterodimer of $\mathrm{Ku} 70-\mathrm{Ku} 80$, which is involved in NHEJ pathway, indicating its potential role in regulating DSB repair (Cooper et al., 2000; Li and Comai, 2000). WRN also plays an important role in maintaining telomere integrity. It has been reported that WRN associates with three of the six members of telomere complex, including telomeric repeat binding factor $1 / 2$ (TRF1/2) and POT1, to modulate exonuclease and helicase activities of WRN during telomeric metabolism (Machwe et al., 2004; Multani and Chang, 2007). Recently, lamin A/C mutations (A57P, R133L, L140R, and E578V) were also reported in autosomal dominant atypical WS where patients presented with more severe phenotypes compared to those associated with WRN (Chen et al., 2003; Csoka et al., 2004; Fukuchi et al., 2004).

Bloom's syndrome is another rare genetic disease characterized by dwarfism, sun-induced erythaema, type II diabetes, narrow face and prominent ears, infertility, benign and malignant tumors. Deaths usually result from neoplasia before the age of 30. RecQ helicase BLM is associated with BS, which is shown to be capable of regulating HR. Upon DNA damage, BLM forms discrete nucleoplasmic foci that co-localize with RAD51 as well as BRCA1-associated genome surveillance complex (BASC) containing BRCA1, MLH1, MRN complex and ATM in mammalian cells (Hickson, 2003). BLM is also involved in the correct localization and activation of topoisomerase III $\alpha$ (Wu et al., 2000). Deletion of Blm in mice results in early embryonic death by E13.5. Blm mutant embryos show growth retardation and Blm-/- ES cells have an elevated HR between sister chromatids (Chester et al., 1998; Guo et al., 2004). Goss et al (Goss et al., 2002) showed that haploinsufficiency of Blm caused 
early development of lymphoma. In another example involving the XPF-XRCC1 endonuclease, a patient bearing a severe XPF mutation presented with dramatic progeroid symptoms. A mouse model for this mutation was generated and expression data from this mouse indicated a shift towards reduced growth hormone/insulin-like growth factor 1 (IGF1) signalling, a known regulator of lifespan. It was proposed that DNA damage accumulation re-allocates resources from growth to life extension by suppressing the somatotroph axis (Niedernhofer et al., 2006).

Hutchinson-Gilford progeria syndrome (HGPS) is an extremely rare severe genetic disorder of early onset premature aging, also referred to as "progeria in childhood". The prevalence is one out of 8 million. So far only about 100 patients have been reported, mainly in western world. Patients with HGPS can only survive for 12-16 years with a mean age of 13.4 years and are clinically characterized with early growth retardation, short stature, lipodystrophy, alopecia, stiff joints, osteolysis, dilated cardiomyopathy and atherosclerosis (Hennekam, 2006; Pollex and Hegele, 2004). A recurrent, de novo, dominant point mutation (1824 C $\rightarrow \mathrm{T})$ of LMNA gene was identified to be responsible for about $76 \%$ reported cases of HGPS. This mutation (G608G) activates a cryptic splicing donor signal in exon 11, leading to 150 nucleotides deletion in mutant transcript and a 50-residue truncation in lamin A protein (Eriksson et al., 2003; Reddel and Weiss, 2004). The 50-residue truncation in lamin A removes the second proteolytic cleavage site of ZMPSTE24 but leaving the CAAX motif unaffected. A detailed study demonstrated that the mutant allele only expressed about $80 \%$ transcripts of total lamin A from the same allele and $\sim 40 \%$ of total lamin A from both alleles (Reddel and Weiss, 2004). Studies in HGPS cells and mice lacking Zmpste24, a metalloprotease processing prelamin A to its mature form, reveal that accumulation of progerin and unprocessed prelamin A leads to either delayed or reduced recruitment of necessary DNA repair proteins, such as 53BP1 and Rad51 to sites of double strand breaks (Liu et al., 2005).

Cockayne syndrome is an autosomal recessive disorder with growth retardation, skin atrophy, sparse hair, cataract, neural system deterioration, but without cancer susceptibility. As described earlier (section 3.3), Cockayne syndrome proteins are involved in TCR.

\begin{tabular}{|l|l|l|l|}
\hline \multicolumn{1}{|c|}{ Human Syndrome } & $\begin{array}{c}\text { Mutated } \\
\text { Gene }\end{array}$ & \multicolumn{1}{|c|}{ Phenotypes } & $\begin{array}{l}\text { Disrupted } \\
\text { DNA repair } \\
\text { pathway }\end{array}$ \\
\hline $\begin{array}{l}\text { Ataxia Telangiectasia } \\
\text { (AT) }\end{array}$ & ATM & $\begin{array}{l}\text { Cerebellar ataxia, telangiectases, oculomotor } \\
\text { apraxia, predisposition to lymphoid } \\
\text { malignancies, leukemias, immune defects, } \\
\text { dilated blood vessel, infertility, metabolic } \\
\text { defects, growth defects }\end{array}$ & $\begin{array}{l}\text { DNA damage } \\
\text { signalling }\end{array}$ \\
\hline $\begin{array}{l}\text { Ataxia Telangiectasia- } \\
\text { like disorder (A-TLD) }\end{array}$ & MRE11 & $\begin{array}{l}\text { Ataxia, oculomotor apraxia, } \\
\text { immunodeficiency }\end{array}$ & $\begin{array}{l}\text { DSB repair, } \\
\text { DNA damage } \\
\text { signalling }\end{array}$ \\
\hline $\begin{array}{l}\text { Nijmegan break } \\
\text { syndrome (NBS) }\end{array}$ & NBS1 & $\begin{array}{l}\text { Microcephaly, immunodeficiency, growth } \\
\text { defects, mental retardation, B cell } \\
\text { lymphoma, facial dysmorphism }\end{array}$ & $\begin{array}{l}\text { DSB repair, } \\
\text { DNA damage } \\
\text { signalling }\end{array}$ \\
\hline NBS-like syndrome & RAD50 & $\begin{array}{l}\text { Microcephaly, facial dysmorphism, growth } \\
\text { defects }\end{array}$ & $\begin{array}{l}\text { DSB repair, } \\
\text { DNA damage } \\
\text { signalling }\end{array}$ \\
\hline
\end{tabular}




\begin{tabular}{|c|c|c|c|}
\hline Human Syndrome & $\begin{array}{l}\text { Mutated } \\
\text { Gene }\end{array}$ & Phenotypes & $\begin{array}{c}\text { Disrupted } \\
\text { DNA repair } \\
\text { pathway } \\
\end{array}$ \\
\hline RIDDLE syndrome & RNF168 & $\begin{array}{l}\text { Radiosensitivity,immunodeficiency, } \\
\text { dysmorphic features and learning } \\
\text { difficulties }\end{array}$ & $\begin{array}{l}\text { DSB repair, } \\
\text { DNA damage } \\
\text { signalling }\end{array}$ \\
\hline $\begin{array}{l}\text { Primary } \\
\text { microcephaly } 1\end{array}$ & $\begin{array}{l}\text { MCPH1/BR } \\
\text { IT1 }\end{array}$ & Microcephaly and mental retardation & $\begin{array}{l}\text { DSB repair, } \\
\text { DNA damage } \\
\text { signalling }\end{array}$ \\
\hline Seckel Syndrome & $\begin{array}{l}\text { ATR, } \\
\text { PCTN, } \\
\text { SCKL2, } \\
\text { SCKL3 }\end{array}$ & $\begin{array}{l}\text { Severe intrauterine growth retardation, } \\
\text { profound microcephaly, a 'bird-like' facial } \\
\text { profile, mental retardation and isolated } \\
\text { skeletal abnormalities dysmorphic facial } \\
\text { features }\end{array}$ & $\begin{array}{l}\text { DSB repair, } \\
\text { DNA damage } \\
\text { signalling }\end{array}$ \\
\hline $\begin{array}{l}\text { Restrictive } \\
\text { dermopathy (RD) }\end{array}$ & $\begin{array}{l}\text { LMNA, } \\
\text { ZMPSTE24 }\end{array}$ & $\begin{array}{l}\text { Tight adherent skin, joint contractures and } \\
\text { respiratory insufficiency, features of } \\
\text { progeroid syndromes and premature death } \\
\text { during gestation }\end{array}$ & DSB repair \\
\hline $\begin{array}{l}\text { Hutchinson-Gilford } \\
\text { progeria syndrome }\end{array}$ & LMNA & $\begin{array}{l}\text { Progeria (early growth retardation, short } \\
\text { stature, lipodystrophy, alopecia, stiff joints, } \\
\text { osteolysis, dilated cardiomyopathy and } \\
\text { atherosclerosis) }\end{array}$ & $\begin{array}{l}\text { DSB repair, } \\
\text { DNA damage } \\
\text { signalling }\end{array}$ \\
\hline Li-Fraumeni syndrome & TP53 & $\begin{array}{l}\text { Brain, breast cancer, sarcomas, leukemias, } \\
\text { melanomas and gastrointestinal cancers }\end{array}$ & $\begin{array}{l}\text { DNA damage } \\
\text { signalling }\end{array}$ \\
\hline $\begin{array}{l}\text { Xeroderma } \\
\text { pigmentosum }\end{array}$ & $\begin{array}{l}X P A-X P G \\
P O L H\end{array}$ & $\begin{array}{l}\text { Skin cancer, photosensitivity, } \\
\text { neurodegeneration and microcephaly }\end{array}$ & NER \\
\hline Trichothiodystrophy & $\begin{array}{l}X P B, X P D \\
T T D A\end{array}$ & $\begin{array}{l}\text { Neurodegeneration, hypomyelination, } \\
\text { progeria (cachexia, cataracts, osteoporosis), } \\
\text { microcephaly, and psychomotoric } \\
\text { abnormalities. }\end{array}$ & NER \\
\hline Cockayne syndrome & $\begin{array}{l}C S A, C S B \\
X P B \\
X P D, X P G\end{array}$ & $\begin{array}{l}\text { Microcephaly, neurodegeneration, neuronal } \\
\text { demyelination, microcephaly, progeria (skin } \\
\text { atrophy, sparse hair cachexia, cataracts, } \\
\text { hearing loss, retinopathy), photosensitivity, } \\
\text { growth defects }\end{array}$ & NER \\
\hline $\begin{array}{l}\text { Cerebro-oculo-facio- } \\
\text { skeletal (COFS) } \\
\text { syndrome }\end{array}$ & $\begin{array}{l}X P D, X P G, \\
C S B \\
\text { ERCC1 }\end{array}$ & $\begin{array}{l}\text { Neuronal demyelination and } \\
\text { dysmyelination, brain calcification, } \\
\text { microcephaly, neurodegeneration, progeria } \\
\text { (cataracts, hearing loss, retinopathy), } \\
\text { photosensitivity, growth defects and facial } \\
\text { dysmorphism }\end{array}$ & NER \\
\hline $\begin{array}{l}\text { Ataxia with } \\
\text { oculomotor apraxia } 1 \\
\text { (AOA1) }\end{array}$ & APTX & $\begin{array}{l}\text { Ataxia, neurodegeneration, oculomotor } \\
\text { apraxia, hypercolesterolemia and dysarthria }\end{array}$ & SSB repair \\
\hline $\begin{array}{l}\text { Spinocerebeller ataxia } \\
\text { with axonal } \\
\text { neuropathy (SCAN1) }\end{array}$ & TDP1 & $\begin{array}{l}\text { Ataxia, oculomotor apraxia, cerebellar } \\
\text { atrophy, dysarthria, hypercholesterolemia, } \\
\text { muscle weakness, sensory neuropathy }\end{array}$ & SSB repair \\
\hline $\begin{array}{l}\text { Immunodeficiency } \\
\text { with microcephaly }\end{array}$ & $X L F$ & $\begin{array}{l}\text { Growth delay, recurrent infections, } \\
\text { autoimmunity, hypoglobulinemia, } \\
\text { lymphopenia and microcephaly }\end{array}$ & NHEJ \\
\hline
\end{tabular}




\begin{tabular}{|c|c|c|c|}
\hline Human Syndrome & $\begin{array}{l}\text { Mutated } \\
\text { Gene }\end{array}$ & Phenotypes & $\begin{array}{l}\text { Disrupted } \\
\text { DNA repair } \\
\text { pathway }\end{array}$ \\
\hline Ligase IV syndrome & LIG4 & $\begin{array}{l}\text { Microcephaly, developmental and growth } \\
\text { delay, immunodeficiency } \\
\text { (Aggamaglobulinemia, lymphopenia) and } \\
\text { lymphoid malignancies }\end{array}$ & NHEJ \\
\hline $\begin{array}{l}\text { Radiosensitive severe } \\
\text { combined } \\
\text { immunodeficiency } \\
\text { (RS-SCID) }\end{array}$ & ARTEMIS & $\begin{array}{l}\text { Aggamaglobulinemia, lymphopenia, } \\
\text { growth defects }\end{array}$ & NHEJ \\
\hline $\begin{array}{l}\text { Severe combined } \\
\text { immunodeficiency } \\
\text { (SCID) }\end{array}$ & $\begin{array}{l}\text { RAG1, } \\
\text { RAG2 }\end{array}$ & $\begin{array}{l}\text { Aggamaglobulinemia, lymphopenia, } \\
\text { growth defects }\end{array}$ & NHEJ \\
\hline Bloom syndrome & $B L M$ & $\begin{array}{l}\text { Microcephaly, short stature, dysmorphic } \\
\text { feature, elevated predisposition to all } \\
\text { cancers, mild/moderate mental retardation, } \\
\text { immunoglobulin deficiency, infertility, } \\
\text { growth defects }\end{array}$ & HR \\
\hline Werner syndrome & $W R N$ & $\begin{array}{l}\text { Premature aging (short stature, premature } \\
\text { cataract, beaked nose, skin atrophy and } \\
\text { alopecia, loss of adipose tissues) type II } \\
\text { diabetes, osteoporosis, arteriosclerosis, } \\
\text { hypogonadism and predisposition to cancer }\end{array}$ & $\begin{array}{l}\text { HR, BER, } \\
\text { telomere } \\
\text { maintenance }\end{array}$ \\
\hline $\begin{array}{l}\text { Rothmund Thomson } \\
\text { syndrome (RTS) }\end{array}$ & RECQL4 & $\begin{array}{l}\text { Stunted growth, premature aging (cataracts, } \\
\text { grey hair), osteosarcomas, skin cancers, skin } \\
\text { and skeletal abnormalities }\end{array}$ & BER \\
\hline $\begin{array}{l}\text { Early onset breast } \\
\text { cancer }\end{array}$ & BRCA1 & Breast and ovarian cancer & HR \\
\hline $\begin{array}{l}\text { Early onset breast } \\
\text { cancer }\end{array}$ & BRCA2 & $\begin{array}{l}\text { Breast and ovarian cancer, increased } \\
\text { predisposition to prostrate, gastric, } \\
\text { pancreatic cancers and melanoma }\end{array}$ & HR \\
\hline Fanconi anemia & $\begin{array}{l}\text { FANCA- } \\
\text { FANCL, } \\
\text { BRCA2 } \\
(\text { FANCD1) }\end{array}$ & $\begin{array}{l}\text { Congenital abnormalities, pancytopenia, } \\
\text { microcephaly, AML, myelodysplasia, } \\
\text { squamous cell carcinoma of head and neck, } \\
\text { abnormal skin pigmentation, infertility, } \\
\text { limb deformities, renal dysfunction }\end{array}$ & $\begin{array}{l}\text { ICL repair } \\
\text { and HR }\end{array}$ \\
\hline $\begin{array}{l}\text { Hereditary non- } \\
\text { polyposis colorectal } \\
\text { cancer (HNPCC) }\end{array}$ & $\begin{array}{l}\text { MSH2, } \\
\text { MSH3, } \\
\text { MSH6, } \\
\text { MLH1, } \\
\text { PMS2 }\end{array}$ & Colon and gynaecological cancers & MMR \\
\hline $\begin{array}{l}\text { Dyskeratosis } \\
\text { congenita (DKC) }\end{array}$ & $\begin{array}{l}\text { DKC1, } \\
\text { TERC }\end{array}$ & $\begin{array}{l}\text { Progeria (progressive bone marrow failure, } \\
\text { pancytopenia, growth defects, } \\
\text { osteoporosis), abnormal skin pigmentation, } \\
\text { microcephaly, mental retardation } \\
\text { carcinomas }\end{array}$ & $\begin{array}{l}\text { Telomere } \\
\text { maintenance }\end{array}$ \\
\hline
\end{tabular}

Table 1. Human diseases and syndromes caused by defective DNA repair 


\section{Conclusions and future directions}

Much of our current understanding of mammalian DNA damage signalling, checkpoint and repair is based on elegant experiments done using yeast and Xenopus as models. During the past decade, greater insights into the mechanism/regulation of the DDR were obtained using mouse models and human congenital disorders. It is now clear that the DDR pathway is critical for both repairing DNA lesions arising from genotoxic stress, as well as for several developmental processes like VDJ recombination, CSR, SHM and meiosis. Through extensive studies conducted in mouse models and human syndromes, it is now known that the principle phenotypes manifested in diseases associated with defective DNA repair are immunodeficiency, infertility, growth retardation, neurodegeneration, microcephaly, increased cancer predisposition and premature aging. Even so, some caveats in our knowledge exist that need further research. The molecular basis for certain phenotypes associated with DNA repair-related human diseases are not clear. For example, the learning difficulty in RIDDLE patients harbouring mutations in RNF168, skeletal abnormalities in ATR-defective Seckel syndrome and Fanconi anemia patients or insulin resistance and glucose intolerance in ATM-defective patients are some of the phenotypes not fully understood. Perhaps, some of these outcomes are related to tissue-specific novel effectors of the DDR pathway, and future studies are required in this direction. In this regard, it is really interesting that some unexpected substrates of the ATM/ATR pathway were uncovered in an unbiased genome-wide proteomic screen and studies on these substrates are likely to shed light on how the DRR can profoundly influence certain tissue-specific phenotypes. Likewise, recent studies have revealed an amazing complexity in the DDR pathway of stem cells and it seems the mechanistic details of how tissue stem cells respond to DNA damage vary between different stem cells populations. Since tissue stem cells have a critical role in the maintenance of organ homeostasis, any disruption in the genomic integrity of stem cells is likely to elicit diseased states such neurodegeneration, cancer or premature aging, or other specific phenotypes depending on the stem cell from the tissue of origin. In this context, further studies are clearly required to gain a total understanding of the genome maintenance pathways in stem cells.

Apart from providing an in-depth understanding of human diseases, understanding the complexity of the DDR pathway has been harnessed for therapeutic benefit against certain cancer subtypes. The proposed rationale is that the DNA repair pathways and their downstream cellular components have undergone genetic alterations in cancer cells resulting in drug resistance. Hence abrogating or modulating the DDR through the use of DDR inhibitors can sensitize cancer cells to chemotherapy (Al-Ejeh et al., 2010). The most successful example in support of this concept has been the use of PARP inhibitors to sensitize Brca-deficient tumors to chemotherapy by about 1000 fold due to excessive DSBs generated as a result of compromised HR (Bryant et al., 2005). The idea being that the enzyme PARP-1 binds SSBs and BER intermediates to facilitate these repair processes. But in HR-defective Brca1 or Brca2 tumors, PARP inhibitors become particularly toxic due to the accumulation of unrepaired DSBs, while PARP inhibition remains nontoxic to normal cells, due to availability of backup mechanisms. PARP inhibitors are currently undergoing clinical trials in Brca-deficient breast and ovarian cancers. Along similar lines, Chk1 inhibition sensitizes p53-deficient tumors to DNA damaging agents better than p53-wild type cells. Thus, both DNA damaging therapies and DDR-inhibitor therapies can be tailored to the needs of each patient, based on the genetic alteration detected in their tumors. 
In conclusion, great strides have been made towards understanding the DDR and its regulation in the past decade. We now have a detailed understanding of how exactly normal cells maintain their genomic integrity when faced with DNA damaging agents. It is now known that the DDR network is critical for several important physiological processes and for human health as evident by the growing list of human syndromes known to be associated with defective DNA repair. The real future challenge lies in developing a more thorough understanding of the functioning and regulation of DDR across various cell/tissue types and then harnessing this knowledge to develop therapeutics for the better management of human health or, perhaps, even extend life span.

\section{Acknowledgment}

This work was supported by Research Grant Council of Hong Kong (HKU7698/05M, HKU7655/06M, HKU7817/07M, CRF HKU3/07C), Innovation and Technology Fund of Hong Kong (ITS/102/07), Progeria Research Foundation, Natural Science Foundation of China (30672205, 30871440, 30971620), Ministry of Science and Technology of CHINA (973 Projects 2007CB50740).

\section{References}

Ahnesorg, P., P. Smith, and S.P. Jackson. 2006. XLF interacts with the XRCC4-DNA ligase IV complex to promote DNA nonhomologous end-joining. Cell 124:301-313.

Al-Ejeh, F., R. Kumar, A. Wiegmans, S.R. Lakhani, M.P. Brown, and K.K. Khanna. 2010. Harnessing the complexity of DNA-damage response pathways to improve cancer treatment outcomes. Oncogene 29:6085-6098.

Al-Hakim, A., C. Escribano-Diaz, M.C. Landry, L. O'Donnell, S. Panier, R.K. Szilard, and D. Durocher. 2010. The ubiquitous role of ubiquitin in the DNA damage response. DNA Repair (Amst) 9:1229-1240.

Al-Tassan, N., N.H. Chmiel, J. Maynard, N. Fleming, A.L. Livingston, G.T. Williams, A.K. Hodges, D.R. Davies, S.S. David, J.R. Sampson, and J.P. Cheadle. 2002. Inherited variants of $\mathrm{MYH}$ associated with somatic G:C-->T:A mutations in colorectal tumors. Nature genetics 30:227-232.

Arias EE, Walter JC. Strength in numbers: preventing rereplication via multiple mechanisms in eukaryotic cells. Genes Dev. 2007 Mar 1;21(5):497-518

Baker, S.M., C.E. Bronner, L. Zhang, A.W. Plug, M. Robatzek, G. Warren, E.A. Elliott, J. Yu, T. Ashley, N. Arnheim, R.A. Flavell, and R.M. Liskay. 1995. Male mice defective in the DNA mismatch repair gene PMS2 exhibit abnormal chromosome synapsis in meiosis. Cell 82:309-319.

Baker, S.M., A.W. Plug, T.A. Prolla, C.E. Bronner, A.C. Harris, X. Yao, D.M. Christie, C. Monell, N. Arnheim, A. Bradley, T. Ashley, and R.M. Liskay. 1996. Involvement of mouse Mlh1 in DNA mismatch repair and meiotic crossing over. Nat Genet 13:336342 .

Bakkenist, C.J., and M.B. Kastan. 2003. DNA damage activates ATM through intermolecular autophosphorylation and dimer dissociation. Nature 421:499-506.

Balajee, A.S., A. Machwe, A. May, M.D. Gray, J. Oshima, G.M. Martin, J.O. Nehlin, R. Brosh, D.K. Orren, and V.A. Bohr. 1999. The Werner syndrome protein is involved in RNA polymerase II transcription. Mol Biol Cell 10:2655-2668. 
Bao, S., Q. Wu, R.E. McLendon, Y. Hao, Q. Shi, A.B. Hjelmeland, M.W. Dewhirst, D.D. Bigner, and J.N. Rich. 2006. Glioma stem cells promote radioresistance by preferential activation of the DNA damage response. Nature 444:756-760.

Barker, N., S. Bartfeld, and H. Clevers. 2010. Tissue-resident adult stem cell populations of rapidly self-renewing organs. Cell Stem Cell 7:656-670.

Barlow, C., S. Hirotsune, R. Paylor, M. Liyanage, M. Eckhaus, F. Collins, Y. Shiloh, J.N. Crawley, T. Ried, D. Tagle, and A. Wynshaw-Boris. 1996. Atm-deficient mice: a paradigm of ataxia telangiectasia. Cell 86:159-171.

Barlow, C., M. Liyanage, P.B. Moens, M. Tarsounas, K. Nagashima, K. Brown, S. Rottinghaus, S.P. Jackson, D. Tagle, T. Ried, and A. Wynshaw-Boris. 1998. Atm deficiency results in severe meiotic disruption as early as leptonema of prophase I. Development 125:4007-4017.

Bartek, J., J. Bartkova, and J. Lukas. 2007. DNA damage signalling guards against activated oncogenes and tumour progression. Oncogene 26:7773-7779.

Bartek, J., and J. Lukas. 2007. DNA damage checkpoints: from initiation to recovery or adaptation. Curr Opin Cell Biol 19:238-245.

Bartkova, J., N. Rezaei, M. Liontos, P. Karakaidos, D. Kletsas, N. Issaeva, L.V. Vassiliou, E. Kolettas, K. Niforou, V.C. Zoumpourlis, M. Takaoka, H. Nakagawa, F. Tort, K. Fugger, F. Johansson, M. Sehested, C.L. Andersen, L. Dyrskjot, T. Orntoft, J. Lukas, C. Kittas, T. Helleday, T.D. Halazonetis, J. Bartek, and V.G. Gorgoulis. 2006. Oncogene-induced senescence is part of the tumorigenesis barrier imposed by DNA damage checkpoints. Nature 444:633-637.

Bassing, C.H., and F.W. Alt. 2004. The cellular response to general and programmed DNA double strand breaks. DNA Repair (Amst) 3:781-796.

Baudat, F., J. Buard, C. Grey, A. Fledel-Alon, C. Ober, M. Przeworski, G. Coop, and B. de Massy. 2010. PRDM9 is a major determinant of meiotic recombination hotspots in humans and mice. Science 327:836-840.

Baudat, F., K. Manova, J.P. Yuen, M. Jasin, and S. Keeney. 2000. Chromosome synapsis defects and sexually dimorphic meiotic progression in mice lacking Spo11. Mol Cell 6:989-998.

Bekker-Jensen, S., C. Lukas, R. Kitagawa, F. Melander, M.B. Kastan, J. Bartek, and J. Lukas. 2006. Spatial organization of the mammalian genome surveillance machinery in response to DNA strand breaks. J Cell Biol 173:195-206.

Bekker-Jensen, S., and N. Mailand. 2010. Assembly and function of DNA double-strand break repair foci in mammalian cells. DNA Repair (Amst) 9:1219-1228.

Biton, S., A. Barzilai, and Y. Shiloh. 2008. The neurological phenotype of ataxiatelangiectasia: solving a persistent puzzle. DNA repair 7:1028-1038.

Blanpain, C., and E. Fuchs. 2009. Epidermal homeostasis: a balancing act of stem cells in the skin. Nature reviews. Molecular cell biology 10:207-217.

Blanpain, C., M. Mohrin, P.A. Sotiropoulou, and E. Passegue. 2011. DNA-damage response in tissue-specific and cancer stem cells. Cell Stem Cell 8:16-29.

Blunt, T., N.J. Finnie, G.E. Taccioli, G.C. Smith, J. Demengeot, T.M. Gottlieb, R. Mizuta, A.J. Varghese, F.W. Alt, P.A. Jeggo, and et al. 1995. Defective DNA-dependent protein kinase activity is linked to $\mathrm{V}(\mathrm{D}) \mathrm{J}$ recombination and DNA repair defects associated with the murine scid mutation. Cell 80:813-823. 
Borde, V., N. Robine, W. Lin, S. Bonfils, V. Geli, and A. Nicolas. 2009. Histone H3 lysine 4 trimethylation marks meiotic recombination initiation sites. EMBO J 28:99-111.

Bredemeyer, A.L., G.G. Sharma, C.Y. Huang, B.A. Helmink, L.M. Walker, K.C. Khor, B. Nuskey, K.E. Sullivan, T.K. Pandita, C.H. Bassing, and B.P. Sleckman. 2006. ATM stabilizes DNA double-strand-break complexes during V(D)J recombination. Nature 442:466-470.

Brosh, R.M., Jr., D.K. Orren, J.O. Nehlin, P.H. Ravn, M.K. Kenny, A. Machwe, and V.A. Bohr. 1999. Functional and physical interaction between WRN helicase and human replication protein A. J Biol Chem 274:18341-18350.

Brosh, R.M., Jr., C. von Kobbe, J.A. Sommers, P. Karmakar, P.L. Opresko, J. Piotrowski, I. Dianova, G.L. Dianov, and V.A. Bohr. 2001. Werner syndrome protein interacts with human flap endonuclease 1 and stimulates its cleavage activity. Embo J 20:5791-5801.

Brown, C.J., S. Lain, C.S. Verma, A.R. Fersht, and D.P. Lane. 2009. Awakening guardian angels: drugging the p53 pathway. Nature reviews. Cancer 9:862-873.

Bryant, H.E., N. Schultz, H.D. Thomas, K.M. Parker, D. Flower, E. Lopez, S. Kyle, M. Meuth, N.J. Curtin, and T. Helleday. 2005. Specific killing of BRCA2-deficient tumours with inhibitors of poly(ADP-ribose) polymerase. Nature 434:913-917.

Buard, J., P. Barthes, C. Grey, and B. de Massy. 2009. Distinct histone modifications define initiation and repair of meiotic recombination in the mouse. EMBO J 28:2616-2624.

Buck, D., L. Malivert, R. de Chasseval, A. Barraud, M.C. Fondaneche, O. Sanal, A. Plebani, J.L. Stephan, M. Hufnagel, F. le Deist, A. Fischer, A. Durandy, J.P. de Villartay, and P. Revy. 2006. Cernunnos, a novel nonhomologous end-joining factor, is mutated in human immunodeficiency with microcephaly. Cell 124:287-299.

Buis, J., Y. Wu, Y. Deng, J. Leddon, G. Westfield, M. Eckersdorff, J.M. Sekiguchi, S. Chang, and D.O. Ferguson. 2008. Mre11 nuclease activity has essential roles in DNA repair and genomic stability distinct from ATM activation. Cell 135:85-96.

Bunting, S.F., E. Callen, N. Wong, H.T. Chen, F. Polato, A. Gunn, A. Bothmer, N. Feldhahn, O. Fernandez-Capetillo, L. Cao, X. Xu, C.X. Deng, T. Finkel, M. Nussenzweig, J.M. Stark, and A. Nussenzweig. 2010. 53BP1 inhibits homologous recombination in Brca1-deficient cells by blocking resection of DNA breaks. Cell 141:243-254.

Caldecott, K.W. 2008. Single-strand break repair and genetic disease. Nat Rev Genet 9:619631.

Casellas, R., A. Nussenzweig, R. Wuerffel, R. Pelanda, A. Reichlin, H. Suh, X.F. Qin, E. Besmer, A. Kenter, K. Rajewsky, and M.C. Nussenzweig. 1998. Ku80 is required for immunoglobulin isotype switching. EMBO J 17:2404-2411.

Celeste, A., S. Petersen, P.J. Romanienko, O. Fernandez-Capetillo, H.T. Chen, O.A. Sedelnikova, B. Reina-San-Martin, V. Coppola, E. Meffre, M.J. Difilippantonio, C. Redon, D.R. Pilch, A. Olaru, M. Eckhaus, R.D. Camerini-Otero, L. Tessarollo, F. Livak, K. Manova, W.M. Bonner, M.C. Nussenzweig, and A. Nussenzweig. 2002. Genomic instability in mice lacking histone H2AX. Science 296:922-927.

Chaudhuri, J., M. Tian, C. Khuong, K. Chua, E. Pinaud, and F.W. Alt. 2003. Transcriptiontargeted DNA deamination by the AID antibody diversification enzyme. Nature 422:726-730. 
Chen, L., L. Lee, B.A. Kudlow, H.G. Dos Santos, O. Sletvold, Y. Shafeghati, E.G. Botha, A. Garg, N.B. Hanson, G.M. Martin, I.S. Mian, B.K. Kennedy, and J. Oshima. 2003. LMNA mutations in atypical Werner's syndrome. Lancet 362:440-445.

Chester, N., F. Kuo, C. Kozak, C.D. O'Hara, and P. Leder. 1998. Stage-specific apoptosis, developmental delay, and embryonic lethality in mice homozygous for a targeted disruption in the murine Bloom's syndrome gene. Genes Dev 12:3382-3393.

Chun, H.H., and R.A. Gatti. 2004. Ataxia-telangiectasia, an evolving phenotype. DNA Repair (Amst) 3:1187-1196.

Ciccia, A., and S.J. Elledge. 2010. The DNA damage response: making it safe to play with knives. Mol Cell 40:179-204.

Clarke, M.F., and M. Fuller. 2006. Stem cells and cancer: two faces of eve. Cell 124:1111-1115.

Cleaver, J.E. 2005. Cancer in xeroderma pigmentosum and related disorders of DNA repair. Nature reviews. Cancer 5:564-573.

Cooper, M.P., A. Machwe, D.K. Orren, R.M. Brosh, D. Ramsden, and V.A. Bohr. 2000. Ku complex interacts with and stimulates the Werner protein. Genes Dev 14:907-912.

Csoka, A.B., H. Cao, P.J. Sammak, D. Constantinescu, G.P. Schatten, and R.A. Hegele. 2004. Novel lamin A/C gene (LMNA) mutations in atypical progeroid syndromes. J Med Genet 41:304-308.

Cui, X., Y. Yu, S. Gupta, Y.M. Cho, S.P. Lees-Miller, and K. Meek. 2005. Autophosphorylation of DNA-dependent protein kinase regulates DNA end processing and may also alter double-strand break repair pathway choice. Mol Cell Biol 25:10842-10852.

Daniel, J.A., M. Pellegrini, J.H. Lee, T.T. Paull, L. Feigenbaum, and A. Nussenzweig. 2008. Multiple autophosphorylation sites are dispensable for murine ATM activation in vivo. J Cell Biol 183:777-783.

de Vries, S.S., E.B. Baart, M. Dekker, A. Siezen, D.G. de Rooij, P. de Boer, and H. te Riele. 1999. Mouse MutS-like protein Msh5 is required for proper chromosome synapsis in male and female meiosis. Genes Dev 13:523-531.

Denchi, E.L. 2009. Give me a break: how telomeres suppress the DNA damage response. DNA repair 8:1118-1126.

Di Noia, J.M., and M.S. Neuberger. 2007. Molecular mechanisms of antibody somatic hypermutation. Annual review of biochemistry 76:1-22.

Diehn, M., R.W. Cho, N.A. Lobo, T. Kalisky, M.J. Dorie, A.N. Kulp, D. Qian, J.S. Lam, L.E. Ailles, M. Wong, B. Joshua, M.J. Kaplan, I. Wapnir, F.M. Dirbas, G. Somlo, C. Garberoglio, B. Paz, J. Shen, S.K. Lau, S.R. Quake, J.M. Brown, I.L. Weissman, and M.F. Clarke. 2009. Association of reactive oxygen species levels and radioresistance in cancer stem cells. Nature 458:780-783.

DiGiovanna, A.G. 2000. Human Aging: Biological Perspectives. McGraw-Hill, New York.

Digweed, M., and K. Sperling. 2004. Nijmegen breakage syndrome: clinical manifestation of defective response to DNA double-strand breaks. DNA Repair (Amst) 3:1207-1217.

Dillon, L.W., A.A. Burrow, and Y.H. Wang. 2010. DNA instability at chromosomal fragile sites in cancer. Curr Genomics 11:326-337.

Edelmann, W., P.E. Cohen, M. Kane, K. Lau, B. Morrow, S. Bennett, A. Umar, T. Kunkel, G. Cattoretti, R. Chaganti, J.W. Pollard, R.D. Kolodner, and R. Kucherlapati. 1996. Meiotic pachytene arrest in MLH1-deficient mice. Cell 85:1125-1134. 
Edelmann, W., P.E. Cohen, B. Kneitz, N. Winand, M. Lia, J. Heyer, R. Kolodner, J.W. Pollard, and R. Kucherlapati. 1999. Mammalian MutS homologue 5 is required for chromosome pairing in meiosis. Nat Genet 21:123-127.

Ege, M., Y. Ma, B. Manfras, K. Kalwak, H. Lu, M.R. Lieber, K. Schwarz, and U. Pannicke. 2005. Omenn syndrome due to ARTEMIS mutations. Blood 105:4179-4186.

Enders, A., P. Fisch, K. Schwarz, U. Duffner, U. Pannicke, E. Nikolopoulos, A. Peters, M. Orlowska-Volk, D. Schindler, W. Friedrich, B. Selle, C. Niemeyer, and S. Ehl. 2006. A severe form of human combined immunodeficiency due to mutations in DNA ligase IV. J Immunol 176:5060-5068.

Eriksson, M., W.T. Brown, L.B. Gordon, M.W. Glynn, J. Singer, L. Scott, M.R. Erdos, C.M. Robbins, T.Y. Moses, P. Berglund, A. Dutra, E. Pak, S. Durkin, A.B. Csoka, M. Boehnke, T.W. Glover, and F.S. Collins. 2003. Recurrent de novo point mutations in lamin A cause Hutchinson-Gilford progeria syndrome. Nature 423:293-298.

Fishel, R., M.K. Lescoe, M.R. Rao, N.G. Copeland, N.A. Jenkins, J. Garber, M. Kane, and R. Kolodner. 1993. The human mutator gene homolog MSH2 and its association with hereditary nonpolyposis colon cancer. Cell 75:1027-1038.

Forand, A., P. Fouchet, J.B. Lahaye, A. Chicheportiche, R. Habert, and J. Bernardino-Sgherri. 2009. Similarities and differences in the in vivo response of mouse neonatal gonocytes and spermatogonia to genotoxic stress. Biol Reprod 80:860-873.

Friedel, A.M., B.L. Pike, and S.M. Gasser. 2009. ATR/Mec1: coordinating fork stability and repair. Curr Opin Cell Biol 21:237-244.

Fukuchi, K., T. Katsuya, K. Sugimoto, M. Kuremura, H.D. Kim, L. Li, and T. Ogihara. 2004. LMNA mutation in a 45 year old Japanese subject with Hutchinson-Gilford progeria syndrome. J Med Genet 41:e67.

Fukui, K. 2010. DNA mismatch repair in eukaryotes and bacteria. J Nucleic Acids 2010:

Gao, Y., Y. Sun, K.M. Frank, P. Dikkes, Y. Fujiwara, K.J. Seidl, J.M. Sekiguchi, G.A. Rathbun, W. Swat, J. Wang, R.T. Bronson, B.A. Malynn, M. Bryans, C. Zhu, J. Chaudhuri, L. Davidson, R. Ferrini, T. Stamato, S.H. Orkin, M.E. Greenberg, and F.W. Alt. 1998. A critical role for DNA end-joining proteins in both lymphogenesis and neurogenesis. Cell 95:891-902.

Giovannetti, A., F. Mazzetta, E. Caprini, A. Aiuti, M. Marziali, M. Pierdominici, A. Cossarizza, L. Chessa, E. Scala, I. Quinti, G. Russo, and M. Fiorilli. 2002. Skewed Tcell receptor repertoire, decreased thymic output, and predominance of terminally differentiated T cells in ataxia telangiectasia. Blood 100:4082-4089.

Goodarzi, A.A., Y. Yu, E. Riballo, P. Douglas, S.A. Walker, R. Ye, C. Harer, C. Marchetti, N. Morrice, P.A. Jeggo, and S.P. Lees-Miller. 2006. DNA-PK autophosphorylation facilitates Artemis endonuclease activity. EMBO J 25:3880-3889.

Gorgoulis, V.G., and T.D. Halazonetis. 2010. Oncogene-induced senescence: the bright and dark side of the response. Current opinion in cell biology 22:816-827.

Goss, K.H., M.A. Risinger, J.J. Kordich, M.M. Sanz, J.E. Straughen, L.E. Slovek, A.J. Capobianco, J. German, G.P. Boivin, and J. Groden. 2002. Enhanced tumor formation in mice heterozygous for Blm mutation. Science 297:2051-2053.

Gray, M.D., J.C. Shen, A.S. Kamath-Loeb, A. Blank, B.L. Sopher, G.M. Martin, J. Oshima, and L.A. Loeb. 1997. The Werner syndrome protein is a DNA helicase. Nat Genet 17:100103. 
Grey, C., F. Baudat, and B. de Massy. 2009. Genome-wide control of the distribution of meiotic recombination. PLoS Biol 7:e35.

Gu, Y., S. Jin, Y. Gao, D.T. Weaver, and F.W. Alt. 1997. Ku70-deficient embryonic stem cells have increased ionizing radiosensitivity, defective DNA end-binding activity, and inability to support V(D)J recombination. Proc Natl Acad Sci U S A 94:8076-8081.

Guardavaccaro, D., and M. Pagano. 2006. Stabilizers and destabilizers controlling cell cycle oscillators. Mol Cell 22:1-4.

Guo, C., T.S. Tang, and E.C. Friedberg. 2010. SnapShot: nucleotide excision repair. Cell 140:754-754 e751.

Guo, G., W. Wang, and A. Bradley. 2004. Mismatch repair genes identified using genetic screens in Blm-deficient embryonic stem cells. Nature 429:891-895.

Hanawalt, P.C., and G. Spivak. 2008. Transcription-coupled DNA repair: two decades of progress and surprises. Nat Rev Mol Cell Biol 9:958-970.

Harper, J.W., and S.J. Elledge. 2007. The DNA damage response: ten years after. Mol Cell 28:739-745.

Hartlerode, A.J., and R. Scully. 2009. Mechanisms of double-strand break repair in somatic mammalian cells. The Biochemical journal 423:157-168.

Hasty, P. 2005. The impact of DNA damage, genetic mutation and cellular responses on cancer prevention, longevity and aging: observations in humans and mice. Mech Ageing Dev 126:71-77.

Hayashi, K., K. Yoshida, and Y. Matsui. 2005. A histone H3 methyltransferase controls epigenetic events required for meiotic prophase. Nature 438:374-378.

Hennekam, R.C. 2006. Hutchinson-Gilford progeria syndrome: review of the phenotype. Am J Med Genet A 140:2603-2624.

Hickson, I.D. 2003. RecQ helicases: caretakers of the genome. Nat Rev Cancer 3:169-178.

Hoeijmakers, J.H. 2009. DNA damage, aging, and cancer. The New England journal of medicine 361:1475-1485.

Huang, S., B. Li, M.D. Gray, J. Oshima, I.S. Mian, and J. Campisi. 1998. The premature ageing syndrome protein, WRN, is a 3'-->5' exonuclease. Nat Genet 20:114-116.

Huen, M.S., and J. Chen. 2010. Assembly of checkpoint and repair machineries at DNA damage sites. Trends Biochem Sci 35:101-108.

Huen, M.S., S.M. Sy, and J. Chen. 2010. BRCA1 and its toolbox for the maintenance of genome integrity. Nat Rev Mol Cell Biol 11:138-148.

Jackson, S.P., and J. Bartek. 2009. The DNA-damage response in human biology and disease. Nature 461:1071-1078.

Johnson, K., D.L. Pflugh, D. Yu, D.G. Hesslein, K.I. Lin, A.L. Bothwell, A. ThomasTikhonenko, D.G. Schatz, and K. Calame. 2004. B cell-specific loss of histone 3 lysine 9 methylation in the $\mathrm{V}(\mathrm{H})$ locus depends on Pax5. Nat Immunol 5:853-861.

Kamath-Loeb, A.S., L.A. Loeb, E. Johansson, P.M. Burgers, and M. Fry. 2001. Interactions between the Werner syndrome helicase and DNA polymerase delta specifically facilitate copying of tetraplex and hairpin structures of the d(CGG)n trinucleotide repeat sequence. J Biol Chem 276:16439-16446.

Katyal, S., and P.J. McKinnon. 2008. DNA strand breaks, neurodegeneration and aging in the brain. Mech Ageing Dev 129:483-491. 
Keeney, S., C.N. Giroux, and N. Kleckner. 1997. Meiosis-specific DNA double-strand breaks are catalyzed by Spo11, a member of a widely conserved protein family. Cell 88:375384.

Kitao, H., and M. Takata. 2011. Fanconi anemia: a disorder defective in the DNA damage response. Int J Hematol 93:417-424.

Kneitz, B., P.E. Cohen, E. Avdievich, L. Zhu, M.F. Kane, H. Hou, Jr., R.D. Kolodner, R. Kucherlapati, J.W. Pollard, and W. Edelmann. 2000. MutS homolog 4 localization to meiotic chromosomes is required for chromosome pairing during meiosis in male and female mice. Genes Dev 14:1085-1097.

Kolodner, R.D., and G.T. Marsischky. 1999. Eukaryotic DNA mismatch repair. Curr Opin Genet Dev 9:89-96.

Kracker, S., Y. Bergmann, I. Demuth, P.O. Frappart, G. Hildebrand, R. Christine, Z.Q. Wang, K. Sperling, M. Digweed, and A. Radbruch. 2005. Nibrin functions in Ig classswitch recombination. Proc Natl Acad Sci U S A 102:1584-1589.

Kramer, B., W. Kramer, M.S. Williamson, and S. Fogel. 1989. Heteroduplex DNA correction in Saccharomyces cerevisiae is mismatch specific and requires functional PMS genes. Mol Cell Biol 9:4432-4440.

Kunkel, T.A., and D.A. Erie. 2005. DNA mismatch repair. Annu Rev Biochem 74:681-710.

Lahdesmaki, A., A.M. Taylor, K.H. Chrzanowska, and Q. Pan-Hammarstrom. 2004. Delineation of the role of the Mre11 complex in class switch recombination. J Biol Chem 279:16479-16487.

Larrea, A.A., S.A. Lujan, and T.A. Kunkel. 2010. SnapShot: DNA mismatch repair. Cell 141:730 e731.

Leach, F.S., N.C. Nicolaides, N. Papadopoulos, B. Liu, J. Jen, R. Parsons, P. Peltomaki, P. Sistonen, L.A. Aaltonen, M. Nystrom-Lahti, and et al. 1993. Mutations of a mutS homolog in hereditary nonpolyposis colorectal cancer. Cell 75:1215-1225.

Lebel, M., E.A. Spillare, C.C. Harris, and P. Leder. 1999. The Werner syndrome gene product co-purifies with the DNA replication complex and interacts with PCNA and topoisomerase I. J Biol Chem 274:37795-37799.

Lee, J.H., and T.T. Paull. 2004. Direct activation of the ATM protein kinase by the Mre11/Rad50/Nbs1 complex. Science 304:93-96.

Li, B., and L. Comai. 2000. Functional interaction between $\mathrm{Ku}$ and the werner syndrome protein in DNA end processing. J Biol Chem 275:28349-28352.

Li, L., E. Salido, Y. Zhou, S. Bhattacharyya, S.M. Yannone, E. Dunn, J. Meneses, A.J. Feeney, and M.J. Cowan. 2005. Targeted disruption of the Artemis murine counterpart results in SCID and defective $\mathrm{V}(\mathrm{D}) \mathrm{J}$ recombination that is partially corrected with bone marrow transplantation. J Immunol 174:2420-2428.

Libby, B.J., L.G. Reinholdt, and J.C. Schimenti. 2003. Positional cloning and characterization of Mei1, a vertebrate-specific gene required for normal meiotic chromosome synapsis in mice. Proc Natl Acad Sci U S A 100:15706-15711.

Lieber, M.R. 2010. The mechanism of double-strand DNA break repair by the nonhomologous DNA end-joining pathway. Annu Rev Biochem 79:181-211.

Lieber, M.R., and T.E. Wilson. 2010. SnapShot: Nonhomologous DNA end joining (NHEJ). Cell 142:496-496 e491.

Lindahl, T. 1993. Instability and decay of the primary structure of DNA. Nature 362:709-715. 
Lipkin, S.M., P.B. Moens, V. Wang, M. Lenzi, D. Shanmugarajah, A. Gilgeous, J. Thomas, J. Cheng, J.W. Touchman, E.D. Green, P. Schwartzberg, F.S. Collins, and P.E. Cohen. 2002. Meiotic arrest and aneuploidy in MLH3-deficient mice. Nat Genet 31:385-390.

Liu, B., J. Wang, K.M. Chan, W.M. Tjia, W. Deng, X. Guan, J.D. Huang, K.M. Li, P.Y. Chau, D.J. Chen, D. Pei, A.M. Pendas, J. Cadinanos, C. Lopez-Otin, H.F. Tse, C. Hutchison, J. Chen, Y. Cao, K.S. Cheah, K. Tryggvason, and Z. Zhou. 2005. Genomic instability in laminopathy-based premature aging. Nat Med 11:780-785.

Liu, Y., R. Subrahmanyam, T. Chakraborty, R. Sen, and S. Desiderio. 2007. A plant homeodomain in RAG-2 that binds Hypermethylated lysine 4 of histone H3 is necessary for efficient antigen-receptor-gene rearrangement. Immunity 27:561-571.

Lopez-Contreras, A.J., and O. Fernandez-Capetillo. 2010. The ATR barrier to replicationborn DNA damage. DNA Repair (Amst) 9:1249-1255.

Lukas, J., C. Lukas, and J. Bartek. 2004. Mammalian cell cycle checkpoints: signalling pathways and their organization in space and time. DNA Repair (Amst) 3:997-1007.

Luo, G., M.S. Yao, C.F. Bender, M. Mills, A.R. Bladl, A. Bradley, and J.H. Petrini. 1999. Disruption of mRad50 causes embryonic stem cell lethality, abnormal embryonic development, and sensitivity to ionizing radiation. Proc Natl Acad Sci U S A 96:73767381.

Machwe, A., L. Xiao, and D.K. Orren. 2004. TRF2 recruits the Werner syndrome (WRN) exonuclease for processing of telomeric DNA. Oncogene 23:149-156.

Mahaney, B.L., K. Meek, and S.P. Lees-Miller. 2009. Repair of ionizing radiation-induced DNA double-strand breaks by non-homologous end-joining. Biochem J 417:639-650.

Mailand, N., S. Bekker-Jensen, H. Faustrup, F. Melander, J. Bartek, C. Lukas, and J. Lukas. 2007. RNF8 ubiquitylates histones at DNA double-strand breaks and promotes assembly of repair proteins. Cell 131:887-900.

Mandon-Pepin, B., C. Derbois, F. Matsuda, C. Cotinot, D.J. Wolgemuth, K. Smith, K. McElreavey, A. Nicolas, and M. Fellous. 2002. [Human infertility: meiotic genes as potential candidates]. Gynecol Obstet Fertil 30:817-821.

Manis, J.P., Y. Gu, R. Lansford, E. Sonoda, R. Ferrini, L. Davidson, K. Rajewsky, and F.W. Alt. 1998. Ku70 is required for late B cell development and immunoglobulin heavy chain class switching. J Exp Med 187:2081-2089.

Manis, J.P., J.C. Morales, Z. Xia, J.L. Kutok, F.W. Alt, and P.B. Carpenter. 2004. 53BP1 links DNA damage-response pathways to immunoglobulin heavy chain class-switch recombination. Nat Immunol 5:481-487.

Maslov, A.Y., and J. Vijg. 2009. Genome instability, cancer and aging. Biochimica et biophysica acta 1790:963-969.

Matsuoka, S., B.A. Ballif, A. Smogorzewska, E.R. McDonald, 3rd, K.E. Hurov, J. Luo, C.E. Bakalarski, Z. Zhao, N. Solimini, Y. Lerenthal, Y. Shiloh, S.P. Gygi, and S.J. Elledge. 2007. ATM and ATR substrate analysis reveals extensive protein networks responsive to DNA damage. Science 316:1160-1166.

Maynard, S., S.H. Schurman, C. Harboe, N.C. de Souza-Pinto, and V.A. Bohr. 2009. Base excision repair of oxidative DNA damage and association with cancer and aging. Carcinogenesis 30:2-10.

McKinnon, P.J. 2009. DNA repair deficiency and neurological disease. Nat Rev Neurosci 10:100-112. 
Melcher, R., R. von Golitschek, C. Steinlein, D. Schindler, H. Neitzel, K. Kainer, M. Schmid, and H. Hoehn. 2000. Spectral karyotyping of Werner syndrome fibroblast cultures. Cytogenet Cell Genet 91:180-185.

Michaloglou, C., L.C. Vredeveld, M.S. Soengas, C. Denoyelle, T. Kuilman, C.M. van der Horst, D.M. Majoor, J.W. Shay, W.J. Mooi, and D.S. Peeper. 2005. BRAFE600associated senescence-like cell cycle arrest of human naevi. Nature 436:720-724.

Mihola, O., Z. Trachtulec, C. Vlcek, J.C. Schimenti, and J. Forejt. 2009. A mouse speciation gene encodes a meiotic histone $\mathrm{H} 3$ methyltransferase. Science 323:373-375.

Milyavsky, M., O.I. Gan, M. Trottier, M. Komosa, O. Tabach, F. Notta, E. Lechman, K.G. Hermans, K. Eppert, Z. Konovalova, O. Ornatsky, E. Domany, M.S. Meyn, and J.E. Dick. 2010. A distinctive DNA damage response in human hematopoietic stem cells reveals an apoptosis-independent role for p53 in self-renewal. Cell Stem Cell 7:186197.

Miyamoto, T., E. Koh, N. Sakugawa, H. Sato, H. Hayashi, M. Namiki, and K. Sengoku. 2008. Two single nucleotide polymorphisms in PRDM9 (MEISETZ) gene may be a genetic risk factor for Japanese patients with azoospermia by meiotic arrest. J Assist Reprod Genet 25:553-557.

Mohrin, M., E. Bourke, D. Alexander, M.R. Warr, K. Barry-Holson, M.M. Le Beau, C.G. Morrison, and E. Passegue. 2010. Hematopoietic stem cell quiescence promotes error-prone DNA repair and mutagenesis. Cell Stem Cell 7:174-185.

Moldovan, G.L., and A.D. D'Andrea. 2009. FANCD2 hurdles the DNA interstrand crosslink. Cell 139:1222-1224.

Mombaerts, P., J. Iacomini, R.S. Johnson, K. Herrup, S. Tonegawa, and V.E. Papaioannou. 1992. RAG-1-deficient mice have no mature B and T lymphocytes. Cell 68:869-877.

Moshous, D., I. Callebaut, R. de Chasseval, B. Corneo, M. Cavazzana-Calvo, F. Le Deist, I. Tezcan, O. Sanal, Y. Bertrand, N. Philippe, A. Fischer, and J.P. de Villartay. 2001. Artemis, a novel DNA double-strand break repair/V(D)J recombination protein, is mutated in human severe combined immune deficiency. Cell 105:177-186.

Moynahan, M.E., and M. Jasin. 2010. Mitotic homologous recombination maintains genomic stability and suppresses tumorigenesis. Nat Rev Mol Cell Biol 11:196-207.

Multani, A.S., and S. Chang. 2007. WRN at telomeres: implications for aging and cancer. J Cell Sci 120:713-721.

Munroe, R.J., R.A. Bergstrom, Q.Y. Zheng, B. Libby, R. Smith, S.W. John, K.J. Schimenti, V.L. Browning, and J.C. Schimenti. 2000. Mouse mutants from chemically mutagenized embryonic stem cells. Nat Genet 24:318-321.

Negrini, S., V.G. Gorgoulis, and T.D. Halazonetis. 2010. Genomic instability--an evolving hallmark of cancer. Nature reviews. Molecular cell biology 11:220-228.

Nick McElhinny, S.A., C.M. Snowden, J. McCarville, and D.A. Ramsden. 2000. Ku recruits the XRCC4-ligase IV complex to DNA ends. Mol Cell Biol 20:2996-3003.

Niedernhofer, L.J., G.A. Garinis, A. Raams, A.S. Lalai, A.R. Robinson, E. Appeldoorn, H. Odijk, R. Oostendorp, A. Ahmad, W. van Leeuwen, A.F. Theil, W. Vermeulen, G.T. van der Horst, P. Meinecke, W.J. Kleijer, J. Vijg, N.G. Jaspers, and J.H. Hoeijmakers. 2006. A new progeroid syndrome reveals that genotoxic stress suppresses the somatotroph axis. Nature 444:1038-1043.

Nouspikel, T. 2009. DNA repair in mammalian cells : Nucleotide excision repair: variations on versatility. Cell Mol Life Sci 66:994-1009. 
O'Connell, B.C., and J.W. Harper. 2007. Ubiquitin proteasome system (UPS): what can chromatin do for you? Curr Opin Cell Biol 19:206-214.

O'Driscoll, M., K.M. Cerosaletti, P.M. Girard, Y. Dai, M. Stumm, B. Kysela, B. Hirsch, A. Gennery, S.E. Palmer, J. Seidel, R.A. Gatti, R. Varon, M.A. Oettinger, H. Neitzel, P.A. Jeggo, and P. Concannon. 2001. DNA ligase IV mutations identified in patients exhibiting developmental delay and immunodeficiency. Mol Cell 8:1175-1185.

O'Driscoll, M.F., P.A. Smith, and C.M. Magnusson. 2009. Evaluation of a part-time adult diploma nursing programme - 'Tailor-made' provision? Nurse Educ Today 29:208216.

Osipovich, O., R. Milley, A. Meade, M. Tachibana, Y. Shinkai, M.S. Krangel, and E.M. Oltz. 2004. Targeted inhibition of $\mathrm{V}(\mathrm{D}) \mathrm{J}$ recombination by a histone methyltransferase. Nat Immunol 5:309-316.

Partridge, L., and M. Mangel. 1999. Messages from mortality: the evolution of death rates in the old. Trends in Ecology and Evolution 14:438-442.

Parvanov, E.D., S.H. Ng, P.M. Petkov, and K. Paigen. 2009. Trans-regulation of mouse meiotic recombination hotspots by Rcr1. PLoS Biol 7:e36.

Pei, H., L. Zhang, K. Luo, Y. Qin, M. Chesi, F. Fei, P.L. Bergsagel, L. Wang, Z. You, and Z. Lou. 2011. MMSET regulates histone H4K20 methylation and 53BP1 accumulation at DNA damage sites. Nature 470:124-128.

Peng, A., and J.L. Maller. 2010. Serine/threonine phosphatases in the DNA damage response and cancer. Oncogene 29:5977-5988.

Pollex, R.L., and R.A. Hegele. 2004. Hutchinson-Gilford progeria syndrome. Clin Genet 66:375-381.

Qiu, W., E.B. Carson-Walter, H. Liu, M. Epperly, J.S. Greenberger, G.P. Zambetti, L. Zhang, and J. Yu. 2008. PUMA regulates intestinal progenitor cell radiosensitivity and gastrointestinal syndrome. Cell Stem Cell 2:576-583.

Rastogi, R.P., Richa, A. Kumar, M.B. Tyagi, and R.P. Sinha. 2010. Molecular mechanisms of ultraviolet radiation-induced DNA damage and repair. J Nucleic Acids 2010:592980.

Reddel, C.J., and A.S. Weiss. 2004. Lamin A expression levels are unperturbed at the normal and mutant alleles but display partial splice site selection in Hutchinson-Gilford progeria syndrome. J Med Genet 41:715-717.

Reina-San-Martin, B., H.T. Chen, A. Nussenzweig, and M.C. Nussenzweig. 2004. ATM is required for efficient recombination between immunoglobulin switch regions. J Exp Med 200:1103-1110.

Riballo, E., S.E. Critchlow, S.H. Teo, A.J. Doherty, A. Priestley, B. Broughton, B. Kysela, H. Beamish, N. Plowman, C.F. Arlett, A.R. Lehmann, S.P. Jackson, and P.A. Jeggo. 1999. Identification of a defect in DNA ligase IV in a radiosensitive leukaemia patient. Curr Biol 9:699-702.

Richard, D.J., E. Bolderson, L. Cubeddu, R.I. Wadsworth, K. Savage, G.G. Sharma, M.L. Nicolette, S. Tsvetanov, M.J. McIlwraith, R.K. Pandita, S. Takeda, R.T. Hay, J. Gautier, S.C. West, T.T. Paull, T.K. Pandita, M.F. White, and K.K. Khanna. 2008. Single-stranded DNA-binding protein hSSB1 is critical for genomic stability. Nature 453:677-681.

Richardson, C., N. Horikoshi, and T.K. Pandita. 2004. The role of the DNA double-strand break response network in meiosis. DNA Repair (Amst) 3:1149-1164. 
Rogakou, E.P., D.R. Pilch, A.H. Orr, V.S. Ivanova, and W.M. Bonner. 1998. DNA doublestranded breaks induce histone H2AX phosphorylation on serine 139. J Biol Chem 273:5858-5868.

Romanienko, P.J., and R.D. Camerini-Otero. 2000. The mouse Spo11 gene is required for meiotic chromosome synapsis. Mol Cell 6:975-987.

Salk, D., K. Au, H. Hoehn, and G.M. Martin. 1981. Cytogenetics of Werner's syndrome cultured skin fibroblasts: variegated translocation mosaicism. Cytogenet Cell Genet 30:92-107.

San Filippo, J., P. Sung, and H. Klein. 2008. Mechanism of eukaryotic homologous recombination. Annual review of biochemistry 77:229-257.

Sancar, A., L.A. Lindsey-Boltz, T.H. Kang, J.T. Reardon, J.H. Lee, and N. Ozturk. 2010. Circadian clock control of the cellular response to DNA damage. FEBS letters 584:2618-2625.

Sato, H., T. Miyamoto, L. Yogev, M. Namiki, E. Koh, H. Hayashi, Y. Sasaki, M. Ishikawa, D.J. Lamb, N. Matsumoto, O.S. Birk, N. Niikawa, and K. Sengoku. 2006. Polymorphic alleles of the human MEI1 gene are associated with human azoospermia by meiotic arrest. J Hum Genet 51:533-540.

Schrader, C.E., J.E. Guikema, E.K. Linehan, E. Selsing, and J. Stavnezer. 2007. Activationinduced cytidine deaminase-dependent DNA breaks in class switch recombination occur during G1 phase of the cell cycle and depend upon mismatch repair. J Immunol 179:6064-6071.

Schreiber, V., F. Dantzer, J.C. Ame, and G. de Murcia. 2006. Poly(ADP-ribose): novel functions for an old molecule. Nat Rev Mol Cell Biol 7:517-528.

Schwarz, K., G.H. Gauss, L. Ludwig, U. Pannicke, Z. Li, D. Lindner, W. Friedrich, R.A. Seger, T.E. Hansen-Hagge, S. Desiderio, M.R. Lieber, and C.R. Bartram. 1996. RAG mutations in human B cell-negative SCID. Science 274:97-99.

Scully, R., and D.M. Livingston. 2000. In search of the tumour-suppressor functions of BRCA1 and BRCA2. Nature 408:429-432.

Shiloh, Y. 2003. ATM and related protein kinases: safeguarding genome integrity. Nat Rev Cancer 3:155-168.

Shinkai, Y., G. Rathbun, K.P. Lam, E.M. Oltz, V. Stewart, M. Mendelsohn, J. Charron, M. Datta, F. Young, A.M. Stall, and et al. 1992. RAG-2-deficient mice lack mature lymphocytes owing to inability to initiate V(D)J rearrangement. Cell 68:855-867.

Simsek, D., and M. Jasin. 2010. Alternative end-joining is suppressed by the canonical NHEJ component Xrcc4-ligase IV during chromosomal translocation formation. Nature structural \& molecular biology 17:410-416.

So, S., A.J. Davis, and D.J. Chen. 2009. Autophosphorylation at serine 1981 stabilizes ATM at DNA damage sites. J Cell Biol 187:977-990.

Soulas-Sprauel, P., G. Le Guyader, P. Rivera-Munoz, V. Abramowski, C. Olivier-Martin, C. Goujet-Zalc, P. Charneau, and J.P. de Villartay. 2007. Role for DNA repair factor XRCC4 in immunoglobulin class switch recombination. J Exp Med 204:1717-1727.

Soutoglou, E., and T. Misteli. 2008. Activation of the cellular DNA damage response in the absence of DNA lesions. Science 320:1507-1510.

Starcevic, D., S. Dalal, and J.B. Sweasy. 2004. Is there a link between DNA polymerase beta and cancer? Cell Cycle 3:998-1001.

Stavnezer, J., J.E. Guikema, and C.E. Schrader. 2008. Mechanism and regulation of class switch recombination. Annu Rev Immunol 26:261-292. 
Stefanini, M., E. Botta, M. Lanzafame, and D. Orioli. 2010. Trichothiodystrophy: from basic mechanisms to clinical implications. DNA repair 9:2-10.

Stewart, G.S., S. Panier, K. Townsend, A.K. Al-Hakim, N.K. Kolas, E.S. Miller, S. Nakada, J. Ylanko, S. Olivarius, M. Mendez, C. Oldreive, J. Wildenhain, A. Tagliaferro, L. Pelletier, N. Taubenheim, A. Durandy, P.J. Byrd, T. Stankovic, A.M. Taylor, and D. Durocher. 2009. The RIDDLE syndrome protein mediates a ubiquitin-dependent signaling cascade at sites of DNA damage. Cell 136:420-434.

Stracker, T.H., and J.H. Petrini. 2011. The MRE11 complex: starting from the ends. Nat Rev Mol Cell Biol 12:90-103.

Su, I.H., A. Basavaraj, A.N. Krutchinsky, O. Hobert, A. Ullrich, B.T. Chait, and A. Tarakhovsky. 2003. Ezh2 controls B cell development through histone H3 methylation and Igh rearrangement. Nat Immunol 4:124-131.

Sugasawa, K., Y. Okuda, M. Saijo, R. Nishi, N. Matsuda, G. Chu, T. Mori, S. Iwai, K. Tanaka, and F. Hanaoka. 2005. UV-induced ubiquitylation of XPC protein mediated by UVDDB-ubiquitin ligase complex. Cell 121:387-400.

Suh, E.K., A. Yang, A. Kettenbach, C. Bamberger, A.H. Michaelis, Z. Zhu, J.A. Elvin, R.T. Bronson, C.P. Crum, and F. McKeon. 2006. p63 protects the female germ line during meiotic arrest. Nature 444:624-628.

Sundin, G.W., and M.R. Weigand. 2007. The microbiology of mutability. FEMS Microbiol Lett 277:11-20.

Szilard, L. 1959. On the Nature of the Aging Process. Proc Natl Acad Sci U S A 45:30-45.

Taccioli, G.E., G. Rathbun, E. Oltz, T. Stamato, P.A. Jeggo, and F.W. Alt. 1993. Impairment of $\mathrm{V}(\mathrm{D}) \mathrm{J}$ recombination in double-strand break repair mutants. Science 260:207-210.

Tang, J.B., and R.A. Greenberg. 2010. Connecting the Dots: Interplay Between Ubiquitylation and SUMOylation at DNA Double Strand Breaks. Genes Cancer 1:787-796.

Thonneau, P., S. Marchand, A. Tallec, M.L. Ferial, B. Ducot, J. Lansac, P. Lopes, J.M. Tabaste, and A. Spira. 1991. Incidence and main causes of infertility in a resident population $(1,850,000)$ of three French regions (1988-1989). Hum Reprod 6:811-816.

van der Burg, M., H. Ijspeert, N.S. Verkaik, T. Turul, W.W. Wiegant, K. Morotomi-Yano, P.O. Mari, I. Tezcan, D.J. Chen, M.Z. Zdzienicka, J.J. van Dongen, and D.C. van Gent. 2009. A DNA-PKcs mutation in a radiosensitive T-B- SCID patient inhibits Artemis activation and nonhomologous end-joining. J Clin Invest 119:91-98.

van der Burg, M., L.R. van Veelen, N.S. Verkaik, W.W. Wiegant, N.G. Hartwig, B.H. Barendregt, L. Brugmans, A. Raams, N.G. Jaspers, M.Z. Zdzienicka, J.J. van Dongen, and D.C. van Gent. 2006. A new type of radiosensitive T-B-NK+ severe combined immunodeficiency caused by a LIG4 mutation. J Clin Invest 116:137-145.

van Engelen, B.G., J.A. Hiel, F.J. Gabreels, L.P. van den Heuvel, D.C. van Gent, and C.M. Weemaes. 2001. Decreased immunoglobulin class switching in Nijmegen Breakage syndrome due to the DNA repair defect. Hum Immunol 62:1324-1327.

Venkatesan, R.N., J.H. Bielas, and L.A. Loeb. 2006. Generation of mutator mutants during carcinogenesis. DNA Repair (Amst) 5:294-302.

Viale, A., F. De Franco, A. Orleth, V. Cambiaghi, V. Giuliani, D. Bossi, C. Ronchini, S. Ronzoni, I. Muradore, S. Monestiroli, A. Gobbi, M. Alcalay, S. Minucci, and P.G. Pelicci. 2009. Cell-cycle restriction limits DNA damage and maintains self-renewal of leukaemia stem cells. Nature 457:51-56. 
Villa, A., S. Santagata, F. Bozzi, S. Giliani, A. Frattini, L. Imberti, L.B. Gatta, H.D. Ochs, K. Schwarz, L.D. Notarangelo, P. Vezzoni, and E. Spanopoulou. 1998. Partial V(D)J recombination activity leads to Omenn syndrome. Cell 93:885-896.

Villa, A., C. Sobacchi, L.D. Notarangelo, F. Bozzi, M. Abinun, T.G. Abrahamsen, P.D. Arkwright, M. Baniyash, E.G. Brooks, M.E. Conley, P. Cortes, M. Duse, A. Fasth, A.M. Filipovich, A.J. Infante, A. Jones, E. Mazzolari, S.M. Muller, S. Pasic, G. Rechavi, M.G. Sacco, S. Santagata, M.L. Schroeder, R. Seger, D. Strina, A. Ugazio, J. Valiaho, M. Vihinen, L.B. Vogler, H. Ochs, P. Vezzoni, W. Friedrich, and K. Schwarz. 2001. V(D)J recombination defects in lymphocytes due to RAG mutations: severe immunodeficiency with a spectrum of clinical presentations. Blood 97:81-88.

Wei, K., A.B. Clark, E. Wong, M.F. Kane, D.J. Mazur, T. Parris, N.K. Kolas, R. Russell, H. Hou, Jr., B. Kneitz, G. Yang, T.A. Kunkel, R.D. Kolodner, P.E. Cohen, and W. Edelmann. 2003. Inactivation of Exonuclease 1 in mice results in DNA mismatch repair defects, increased cancer susceptibility, and male and female sterility. Genes Dev 17:603-614.

Weidenheim, K.M., D.W. Dickson, and I. Rapin. 2009. Neuropathology of Cockayne syndrome: Evidence for impaired development, premature aging, and neurodegeneration. Mech Ageing Dev 130:619-636.

Wilson, D.M., 3rd, and V.A. Bohr. 2007. The mechanics of base excision repair, and its relationship to aging and disease. DNA Repair (Amst) 6:544-559.

Woodward, W.A., M.S. Chen, F. Behbod, M.P. Alfaro, T.A. Buchholz, and J.M. Rosen. 2007. WNT/beta-catenin mediates radiation resistance of mouse mammary progenitor cells. Proceedings of the National Academy of Sciences of the United States of America 104:618-623.

Wu, L., S.L. Davies, P.S. North, H. Goulaouic, J.F. Riou, H. Turley, K.C. Gatter, and I.D. Hickson. 2000. The Bloom's syndrome gene product interacts with topoisomerase III. J Biol Chem 275:9636-9644.

Yan, C.T., C. Boboila, E.K. Souza, S. Franco, T.R. Hickernell, M. Murphy, S. Gumaste, M. Geyer, A.A. Zarrin, J.P. Manis, K. Rajewsky, and F.W. Alt. 2007. IgH class switching and translocations use a robust non-classical end-joining pathway. Nature 449:478482.

Yoshida, K., G. Kondoh, Y. Matsuda, T. Habu, Y. Nishimune, and T. Morita. 1998. The mouse RecA-like gene Dmc1 is required for homologous chromosome synapsis during meiosis. Mol Cell 1:707-718.

Yu, C.E., J. Oshima, Y.H. Fu, E.M. Wijsman, F. Hisama, R. Alisch, S. Matthews, J. Nakura, T. Miki, S. Ouais, G.M. Martin, J. Mulligan, and G.D. Schellenberg. 1996. Positional cloning of the Werner's syndrome gene. Science 272:258-262.

Zhang, M., F. Behbod, R.L. Atkinson, M.D. Landis, F. Kittrell, D. Edwards, D. Medina, A. Tsimelzon, S. Hilsenbeck, J.E. Green, A.M. Michalowska, and J.M. Rosen. 2008. Identification of tumor-initiating cells in a p53-null mouse model of breast cancer. Cancer research 68:4674-4682.

Zhang, Y., and M. Jasin. 2011. An essential role for CtIP in chromosomal translocation formation through an alternative end-joining pathway. Nature structural $\mathcal{E}$ molecular biology 18:80-84.

Zhu, J., S. Petersen, L. Tessarollo, and A. Nussenzweig. 2001. Targeted disruption of the Nijmegen breakage syndrome gene NBS1 leads to early embryonic lethality in mice. Curr Biol 11:105-109. 


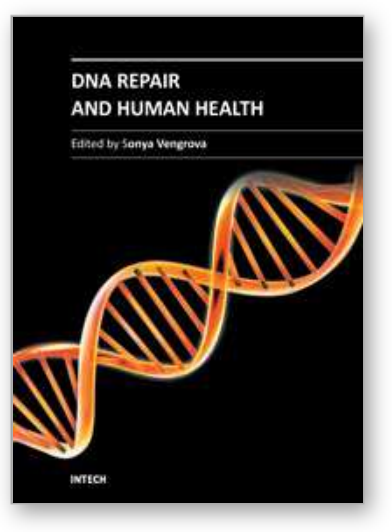

\author{
DNA Repair and Human Health \\ Edited by Dr. Sonya Vengrova
}

ISBN 978-953-307-612-6

Hard cover, 792 pages

Publisher InTech

Published online 26, October, 2011

Published in print edition October, 2011

Over the past decades, great advances have been made in understanding the cellular DNA repair pathways. At the same time, a wealth of descriptive knowledge of human diseases has been accumulated. Now, the basic research of the mechanisms of DNA repair is merging with clinical research, placing the action of the DNA repair pathways in the context of the whole organism. Such integrative approach enables understanding of the disease mechanisms and is invaluable in improving diagnostics and prevention, as well as designing better therapies. This book highlights the central role of DNA repair in human health and well-being. The reviews presented here, contain detailed descriptions of DNA repair pathways, as well as analysis of a large body of evidence addressing links between DNA damage repair and human health. They will be of interest to a broad audience, from molecular biologists working on DNA repair in any model system, to medical researchers.

\title{
How to reference
}

In order to correctly reference this scholarly work, feel free to copy and paste the following:

Vaidehi Krishnan, Baohua Liu and Zhongjun Zhou (2011). DNA Repair, Human Diseases and Aging, DNA Repair and Human Health, Dr. Sonya Vengrova (Ed.), ISBN: 978-953-307-612-6, InTech, Available from: http://www.intechopen.com/books/dna-repair-and-human-health/dna-repair-human-diseases-and-aging

\section{INTECH}

open science | open minds

\author{
InTech Europe \\ University Campus STeP Ri \\ Slavka Krautzeka 83/A \\ 51000 Rijeka, Croatia \\ Phone: +385 (51) 770447 \\ Fax: +385 (51) 686166 \\ www.intechopen.com
}

\author{
InTech China \\ Unit 405, Office Block, Hotel Equatorial Shanghai \\ No.65, Yan An Road (West), Shanghai, 200040, China \\ 中国上海市延安西路65号上海国际贵都大饭店办公楼405单元 \\ Phone: +86-21-62489820 \\ Fax: +86-21-62489821
}


(C) 2011 The Author(s). Licensee IntechOpen. This is an open access article distributed under the terms of the Creative Commons Attribution 3.0 License, which permits unrestricted use, distribution, and reproduction in any medium, provided the original work is properly cited. 